\title{
Criminal Liability of an Entrapped Person Through the Prism of Goals of Punishment
}

\author{
Papuna Guruli \\ PHD candidate in Caucasus international University \\ Attorney-at-Law (General specialisation)
}

\section{ARTICLE INFO}

Article History:

$\begin{array}{ll}\text { Received } & 2.11 .2021 \\ \text { Accepted } & 10.11 .2021 \\ \text { Published } & 20.12 .2021\end{array}$

\section{Keywords:}

Provocation of crime,

The purpose of punishment, Exemption from liability

\section{ABSTRACT}

Present work was written as a part of doctoral research. It aims to generate reasonable arguments on whether it is just to prosecute and punish a person that was entrapped by an agent-provocateur. In other words - does criminal entrapment constitute a substantive defence for an entrapped person or not? In scientific literature the matter is traditionally discussed within the scope of criminal procedure (admissibility of evidence, fair trial etc.) while arguments from substantive criminal law are rarely addressed. Thus, it remains unclear whether the goals of punishment are achievable at all if an entrapped person gets sentenced. Thus, it is necessary to comprehend the subject through the prism of goals of punishment namely: restoration of justice, special prevention of crime and general prevention of crime especially since all three are well-recognised by science of criminal law and current legislation. After detailed and consistent analysis done within research, there are good reasons to conclude that prosecution and following sentencing of an entrapped person:

- Hinders restoration of justice

- Hinders special prevention of crime

- Partially hinders general prevention

- Eventually, all that constitutes an important argument to consider entrapment as a substantive defence for the entrapped person. 


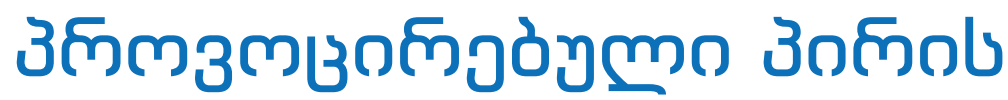

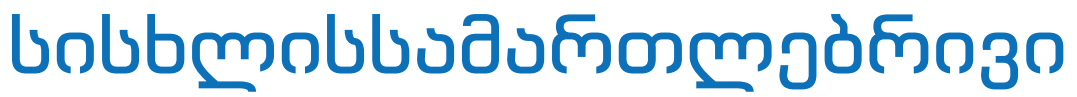 उుbybobdajòmmd̀ -

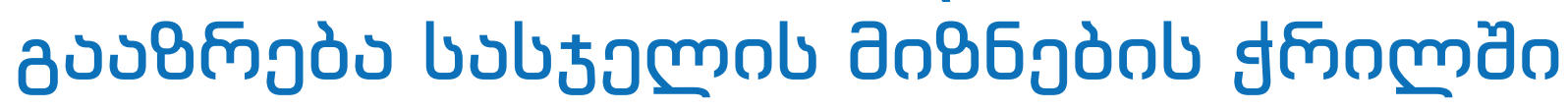

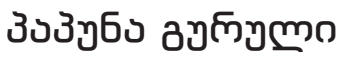

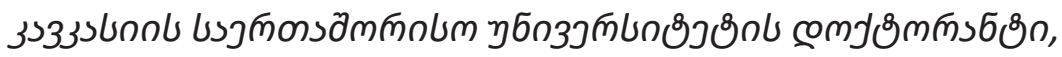

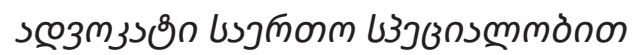

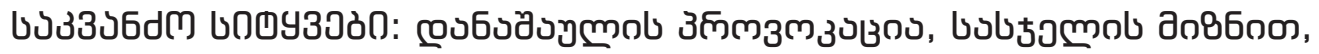
З

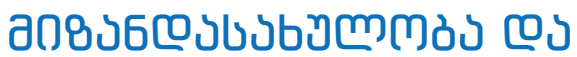

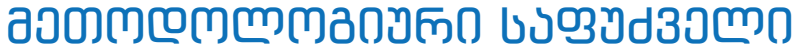

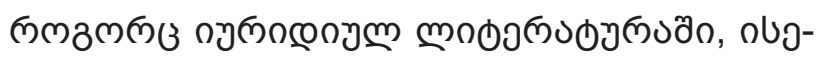

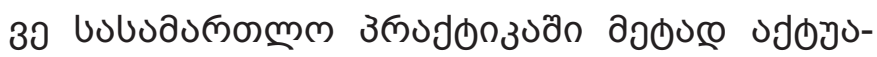

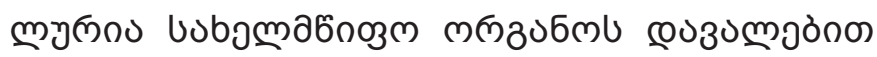

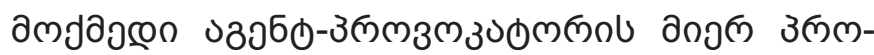

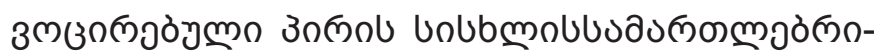

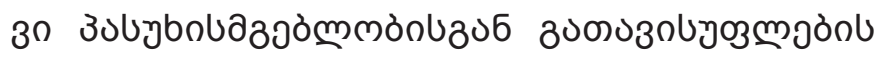

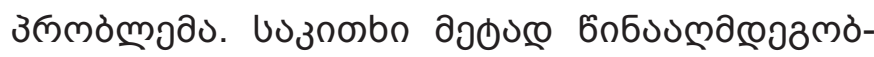

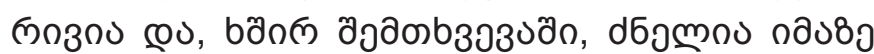

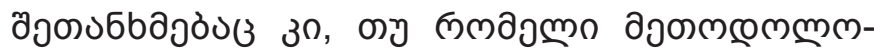

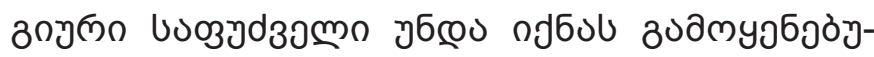

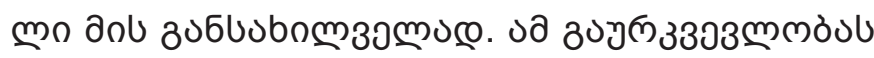

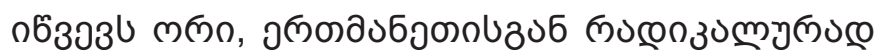

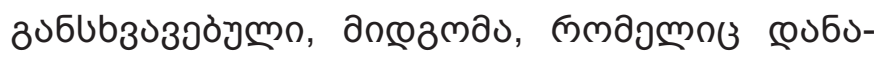

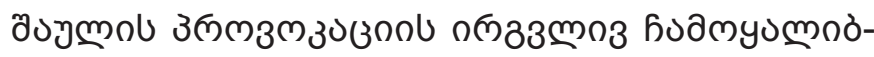

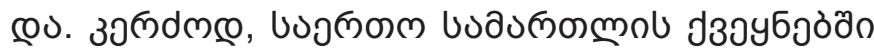

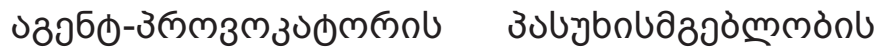

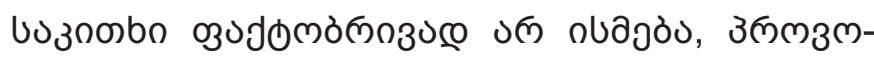

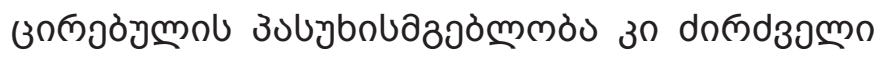

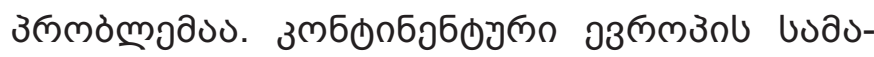

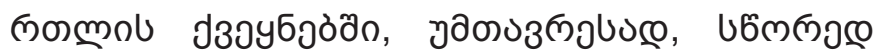

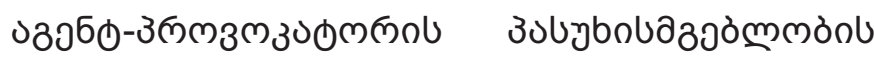

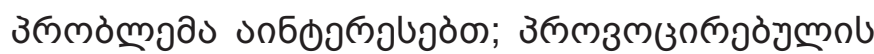

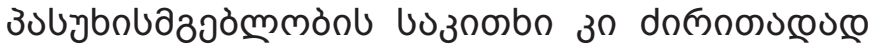

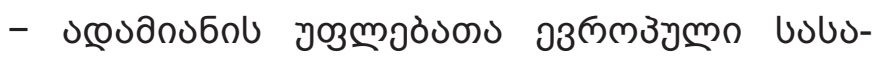

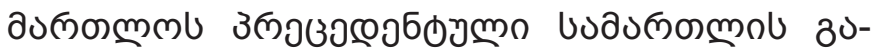

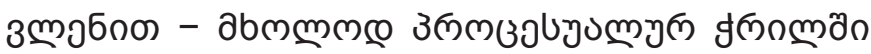

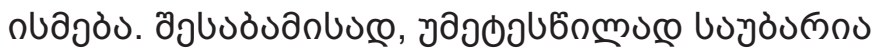

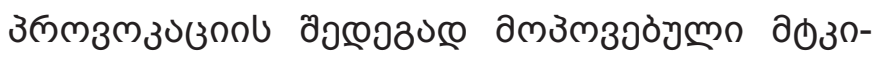

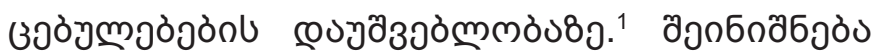

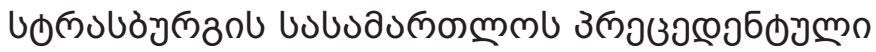

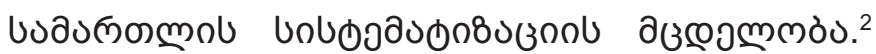

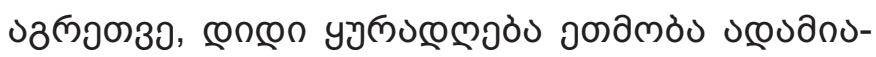

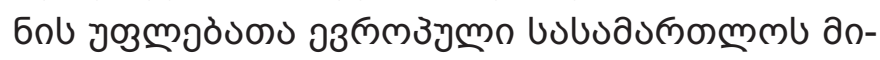

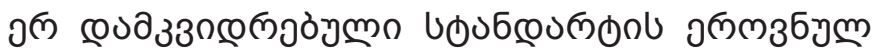

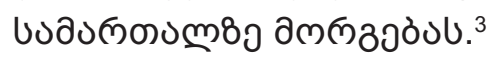

1 Шульгин, С., 2017. Провокація (підбурювання) особи на вчинення злочину працівниками правоохоронного органу як підстава для закриття кримінального проваждення або постановлення виправдувального вироку. Вісник кримінального судочинства. N1/2017, ст. 96-102.

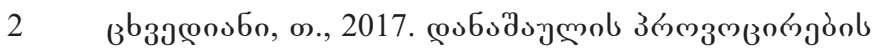

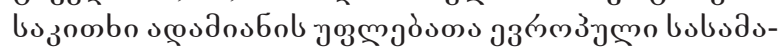

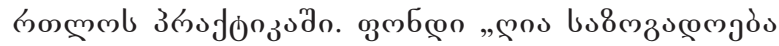

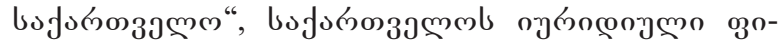

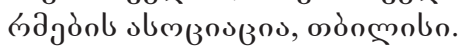

3 Gottschalk, F., 2013. Verfahrenshindernis bei Tatprovokation durch Lockspitzel? Staatliche Tatprovokationen im Lichte der Rechtsprechung des EGMR. StudZR.

Görlitz, F., Hubert, J., Kucher, J, Scheffer, M., Wieser, P., 


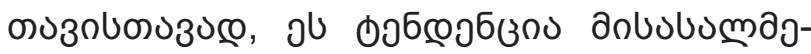

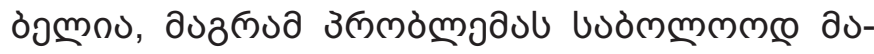

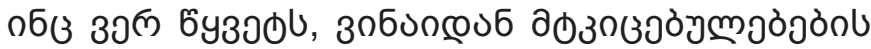

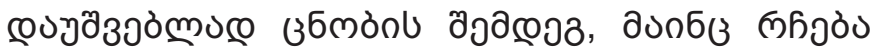

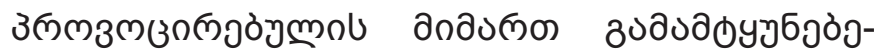

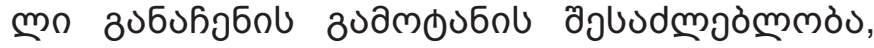

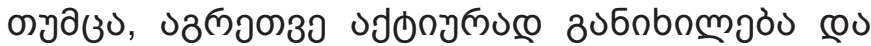

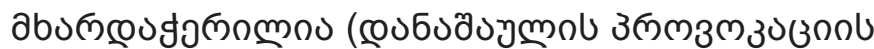

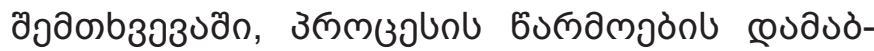

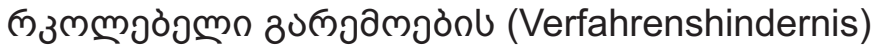

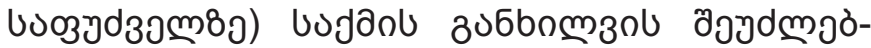

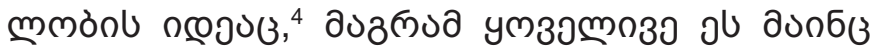

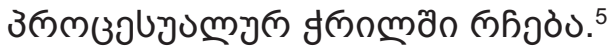

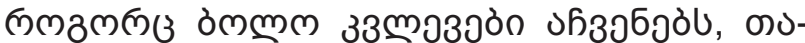

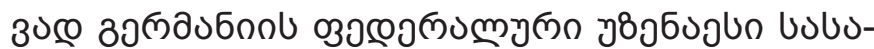

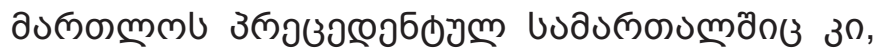

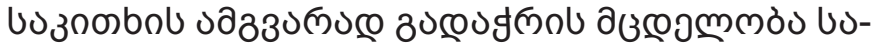

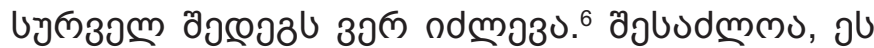

2019. "Tatprovokation" - The Legal Issue of Entrapment in Germany and Possible Solutions. German Law Journal, 2004.

Liewald, K., 2015. Rechtsfolgen unzulässiger Tatprovokation im Hinblick auf die aktuelle Rechtsprechung des EGMR. Dissertation. Universität Wien, Wien.

Esser, R., 2011. Lockspitzel und V-Leute in der Rechtsprechung des EGMR: Strafrechtliche Ermittlungen jenseits der StPO - außerhalb des Gesetzes? Beitrag zum 35. Strafverteidigertag, Berlin.

Heinrich, B., 2016. Staatliche Tatprovokation. DeutschGeorgische Strafrechtszeitschrift. 1/2016, S. 27-28.

Ellbogen, K., 2016. Das ende des Polizeichen Lockspitzeleinsatzes? Studere, Rechtszeitschrift der Universität Potsdam, Ausgabe 16, Frühling/Sommer

Wessels, Beulke, Satzger. 2020. Strafrecht Allgemeiner Teil. Die Straftat und ihr Aufbau. 50, neu bearbeitete Auflage, C.F. Müller, S. 4602-4624.

El-Ghazi M., Zerbes I. 2014. Geschichten von staatlicher Komplizenschaft und evidenten Rechtsbrüchen. Zugleich Anmerkung zu BGH. HRRS, 15 Jahrgang, Ausgabe 6/2014, Nr. 163, S. 209-219

Hübner Y. 2020. Schluss mit der Strafzumessungslösung! Zugl. Bespr. zu EGMR (Akbay u.a. gegen Deutschland). HRRS, 21. Jahrgang, №1163, S. 441-445.

Дударенко, В., 2017. Юридическая природа провокации преступления в уголовном праве. Диссертация, Екатеринбург, стр. 165.

Swoboda, L-S. (July 2016). Der „agent provocateur“ aus verwaltungsstrafrechtlicher Sicht. Zeitschrift der Verwaltungsgerichtsbarkeit. Ausgabe 4, S. 304-310.

Klaus, J., 2021. Das Ende der Strafzumessungslösung nach einer menschenrechtswidrigen Tatprovokation. Zugleich Besprechung von EGMR, Urt. v. 15.10.2020 - 40495/15, 37273/15, 40913/15 (Akbay u.a. v. Deutschland). 16. Volume, Issue 6/2021, S. 388-398.

Jahn, M., (März, 2021) Schriftliche Stellungnahme für die

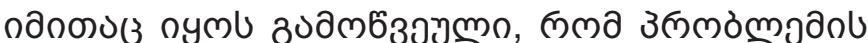

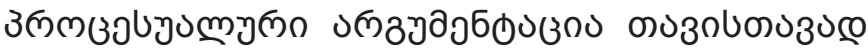

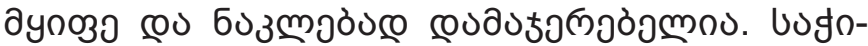

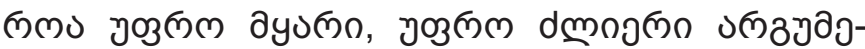

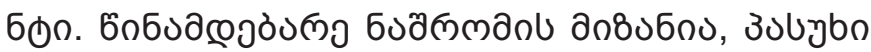

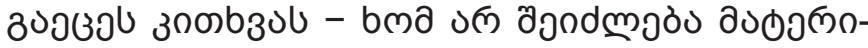

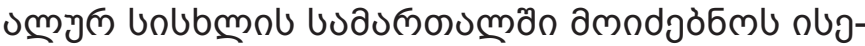

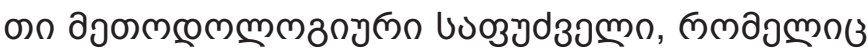

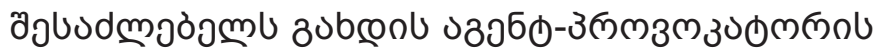

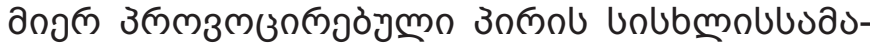

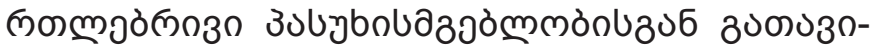

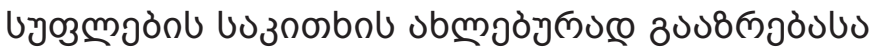

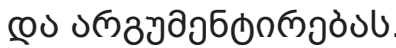

\section{(4) งตักलว}

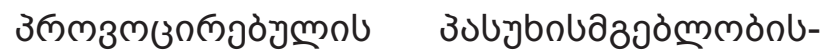

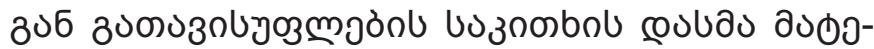

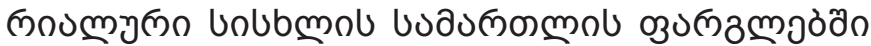

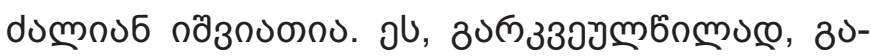

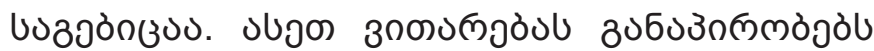

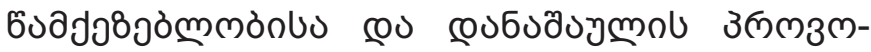

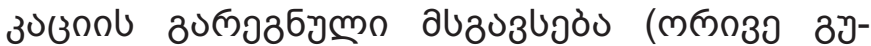
molbamól ubzol couymmnodul couбuàymol

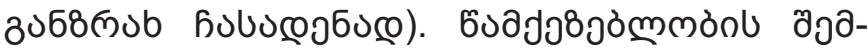

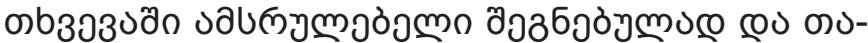

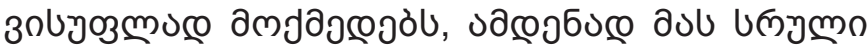

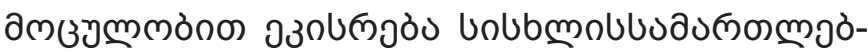

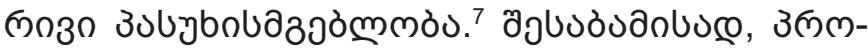

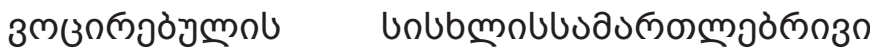

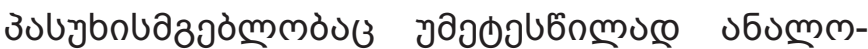

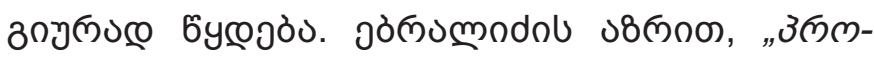

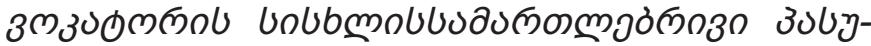

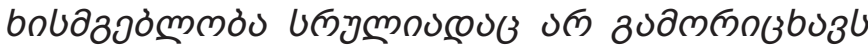

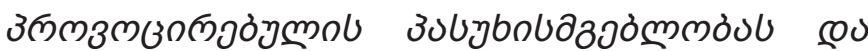

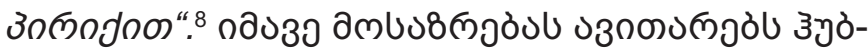

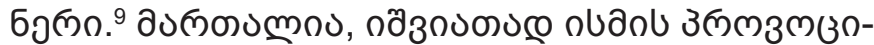

öffentliche Anhörung im Rechtsausschuss des Deutschen Bundestages. Goethe Universität, Frankfurt am Main, S.2-29.

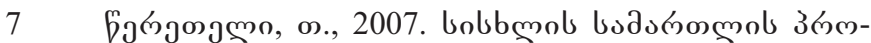

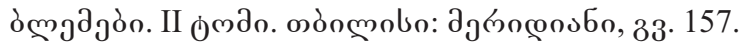

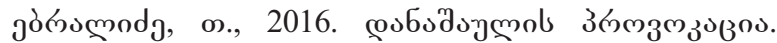

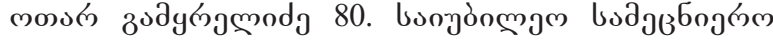
З ऊృ

9 Hübner, Y., 2020. Rechtsstaatswidrig, aber Straflos? Der agent provocateur-Einsatz und seine Strafrechtlichen Konsequenzen. Frankfurt am Mein: Nomos, S. 152. 


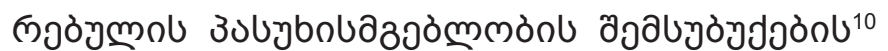

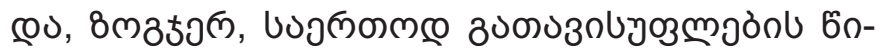

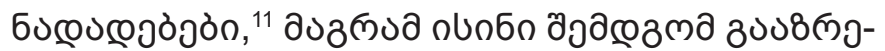

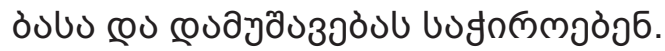

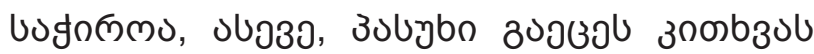

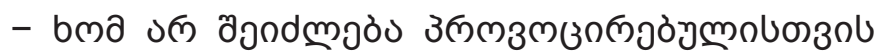

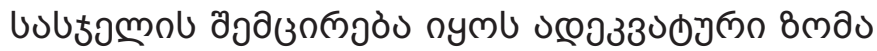

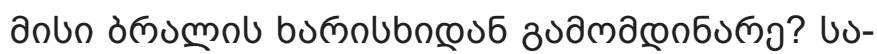

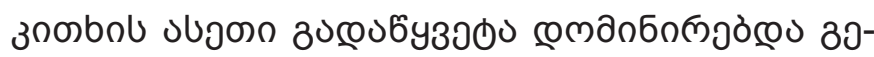

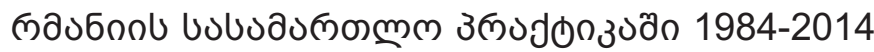

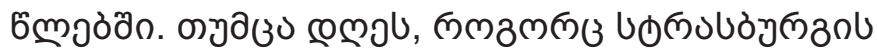

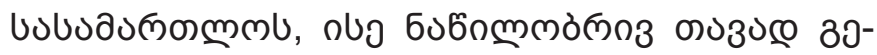

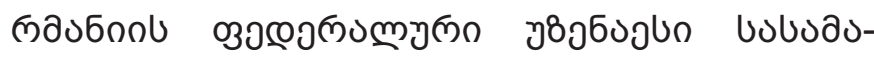

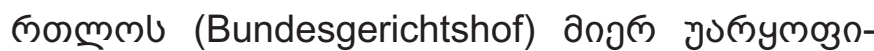

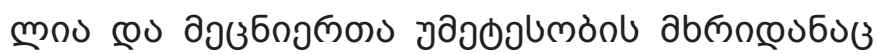

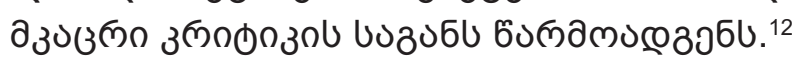

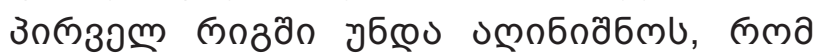

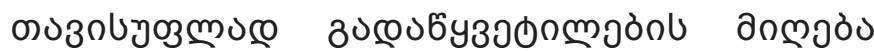

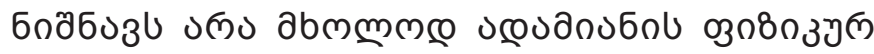

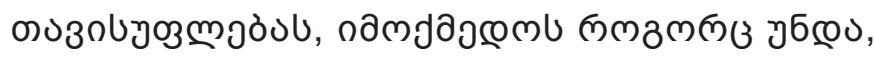

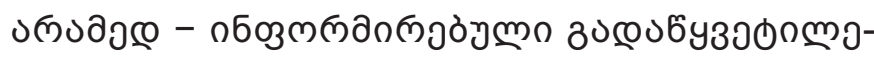

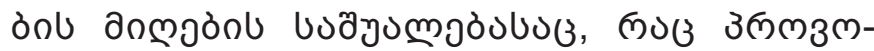

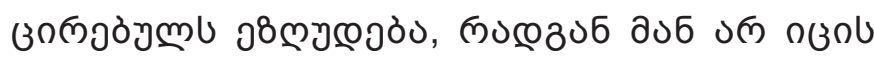

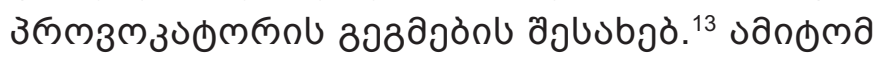

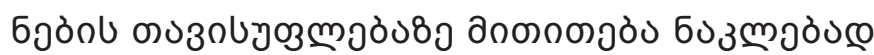

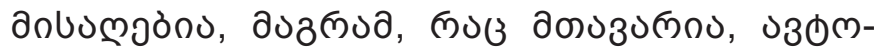

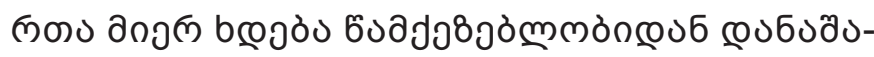

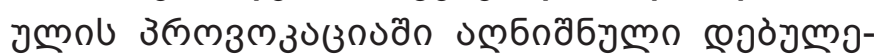

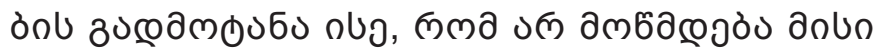

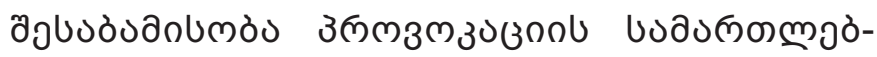

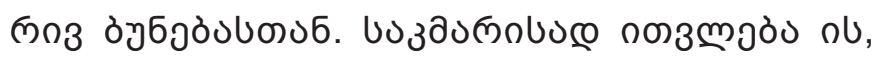

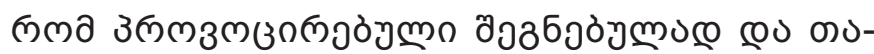

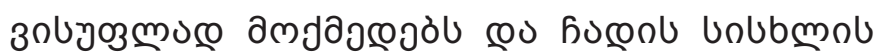

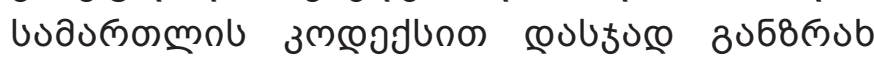

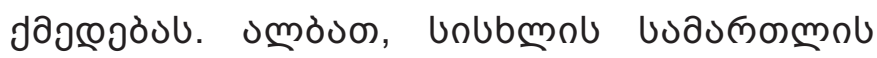

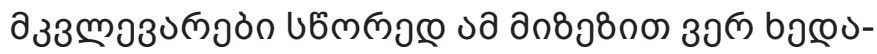

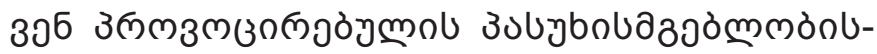

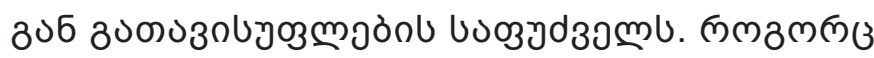

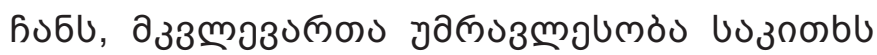

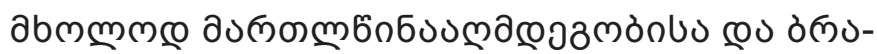

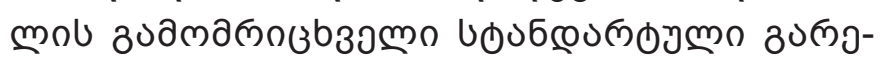

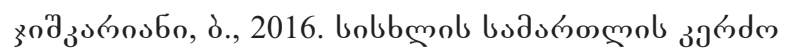

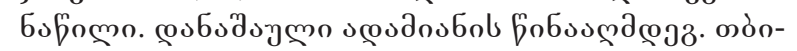

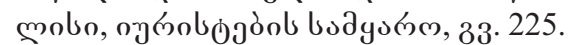

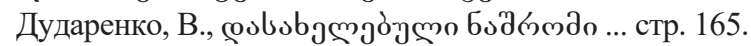

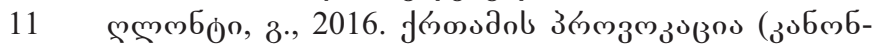

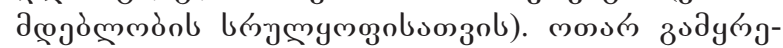

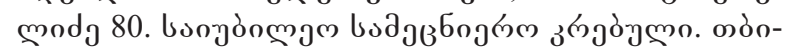

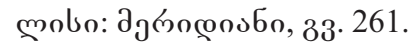

12 Hübner Y. Rechtsstaatswidrig, aber Straflos?.. S. 173-173. 13 oł39, S. 101.

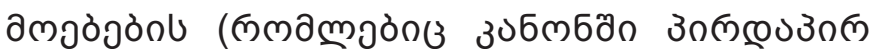

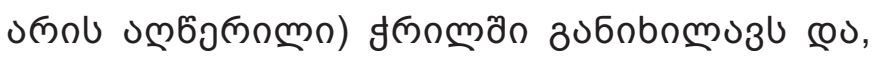

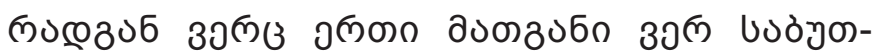

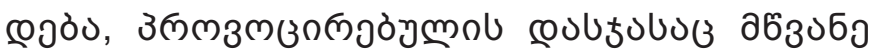

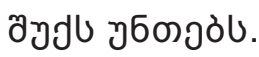

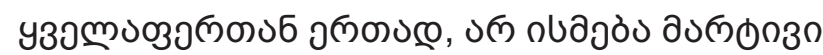

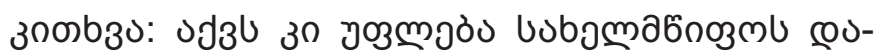

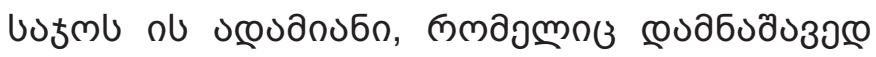

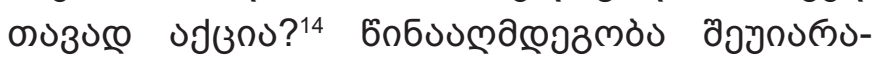

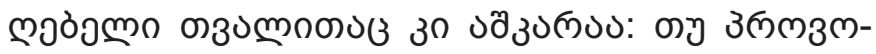

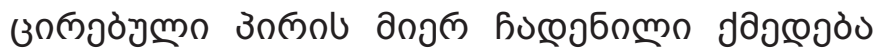

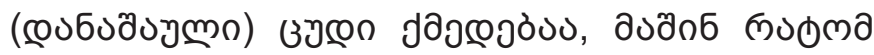

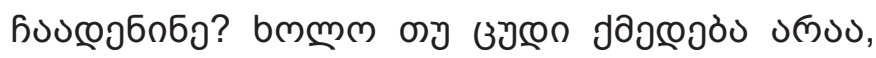

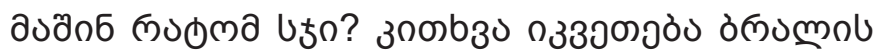

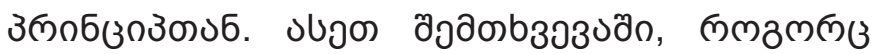

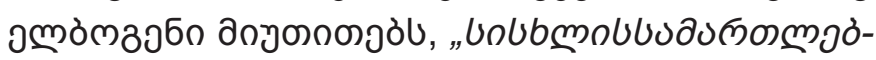

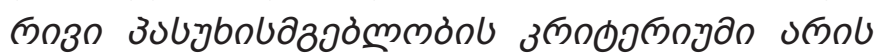

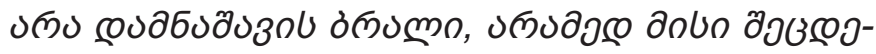
бuscmòu. 15

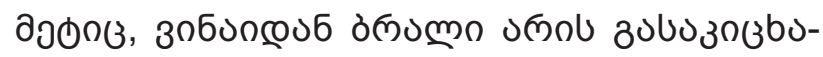

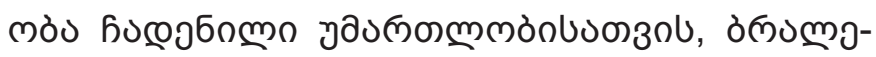

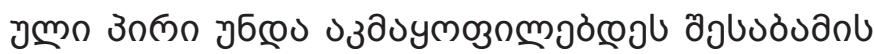

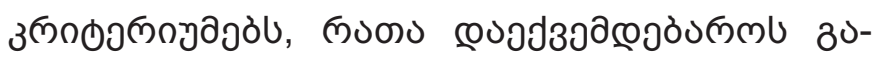

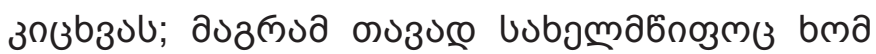

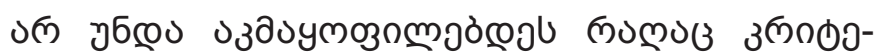

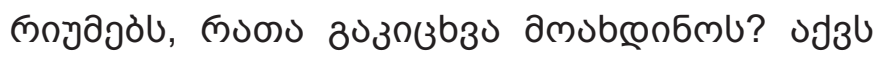

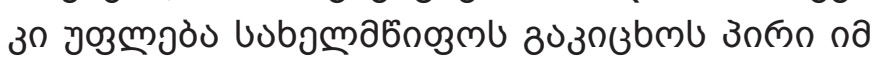

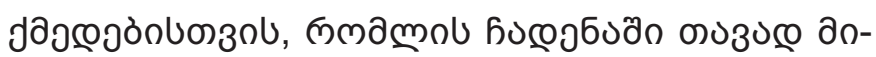

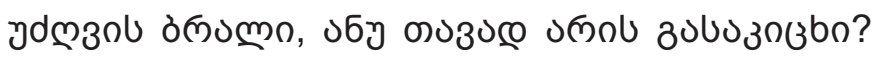

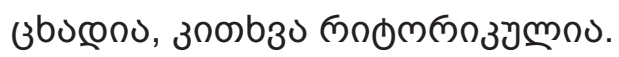

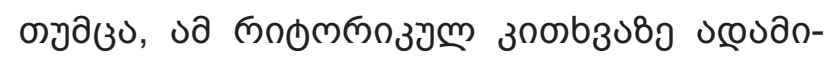

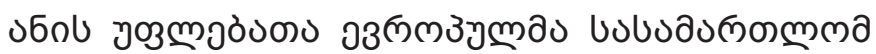

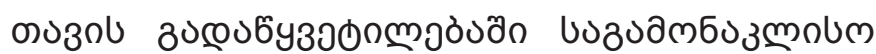

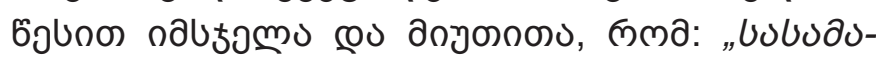

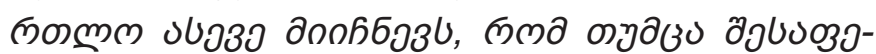

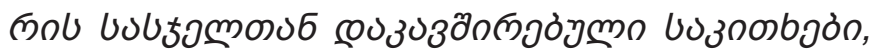

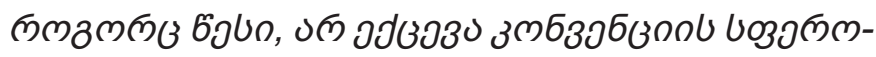

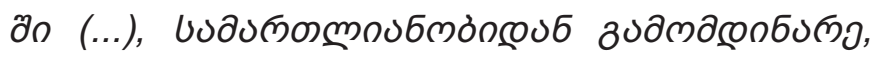

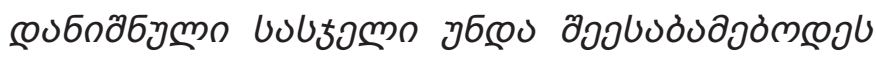

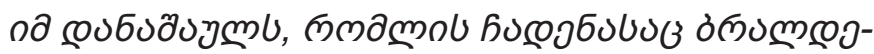

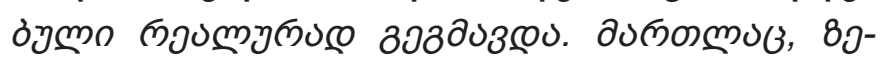

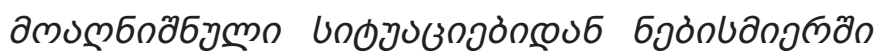

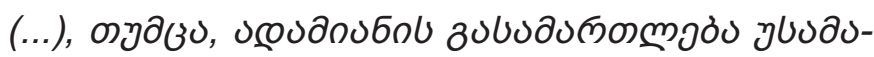

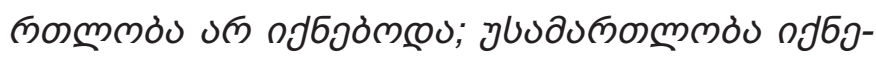

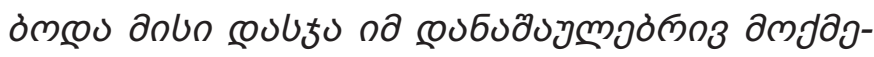

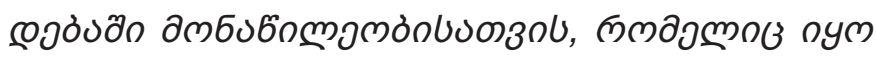

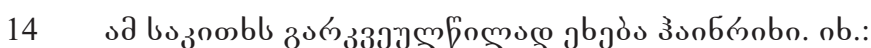
Heinrich, B. Staatliche Tatprovokation ... S. 25.

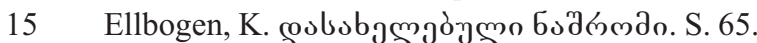




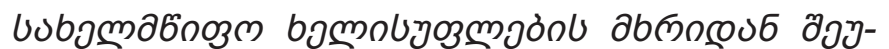

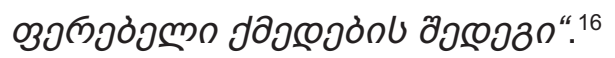

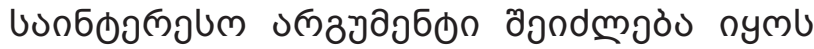

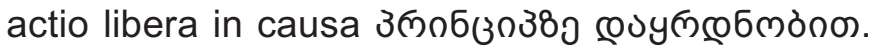

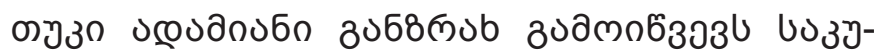

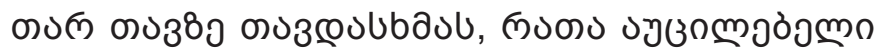

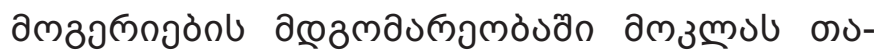

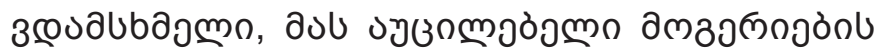

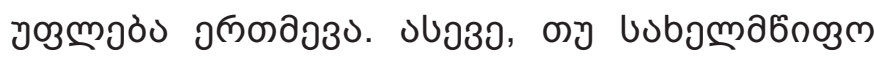

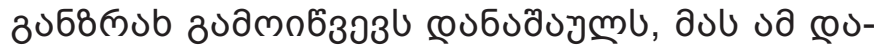

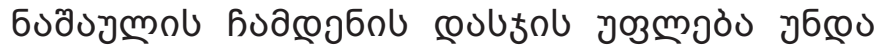

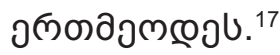

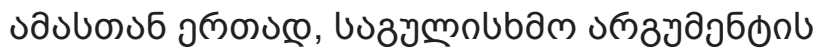

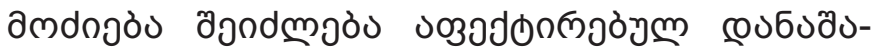

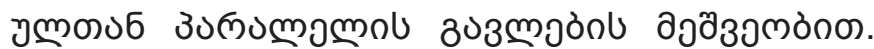

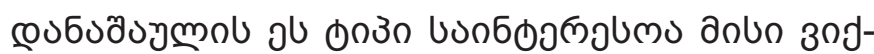

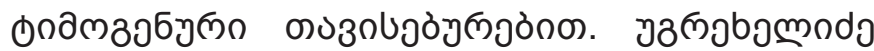

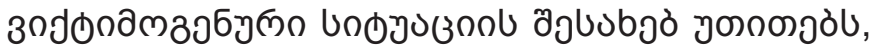

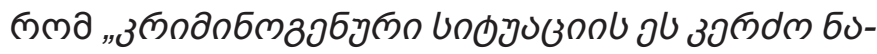

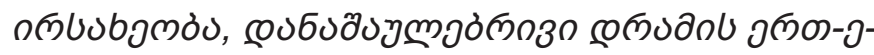

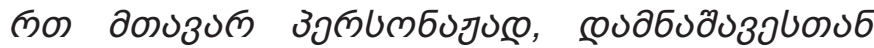

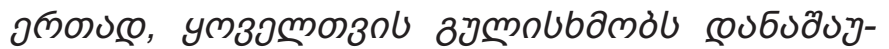

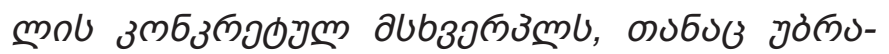

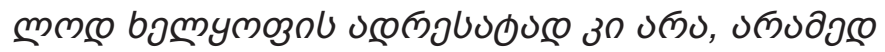

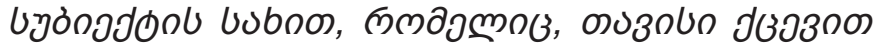

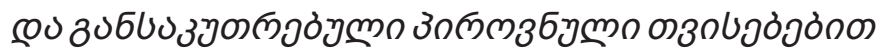

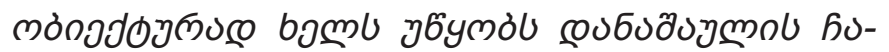

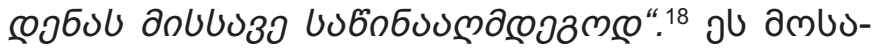

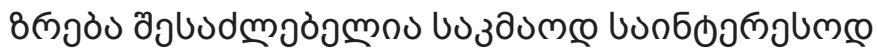

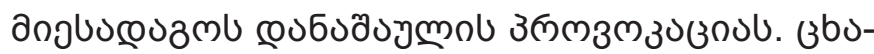

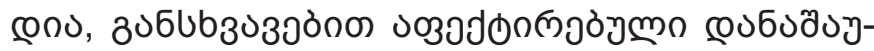

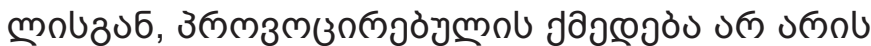

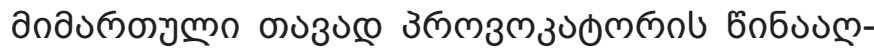

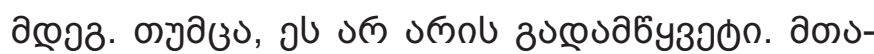

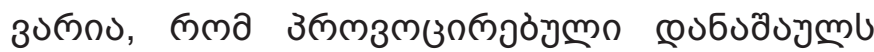

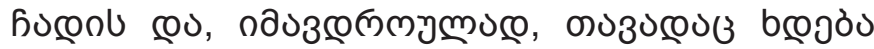

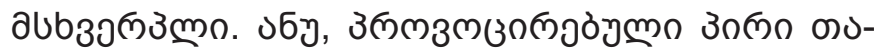

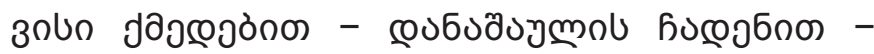

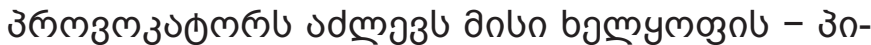

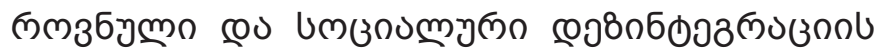

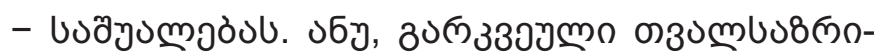

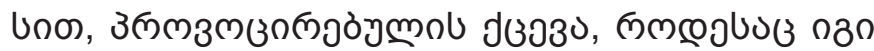

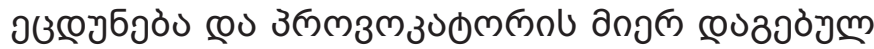

16 ECtHR. CASE OF GRBA v. CROATIA (Application no. 47074/12) 23 November 2017. § 103.

17 Katz, L., 2013. Entrapment Through the Lens of the Actio Libera in Causa. Criminal Law and Philosophy, Volume 7, issue 3, October, pp. 592-595.

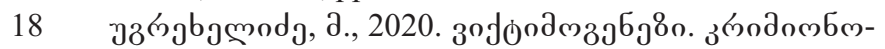
mल3\%, , N1 (15), 33. 24-26.

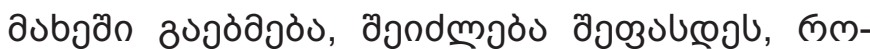

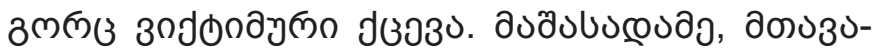

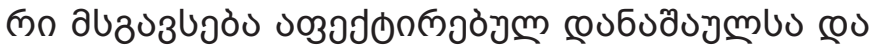

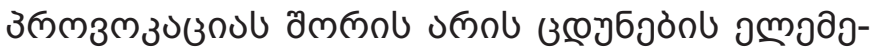

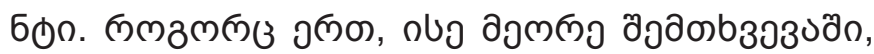

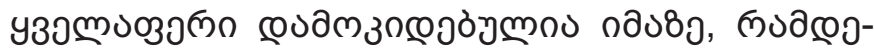

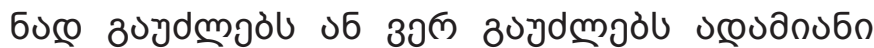

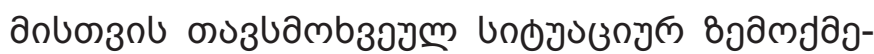

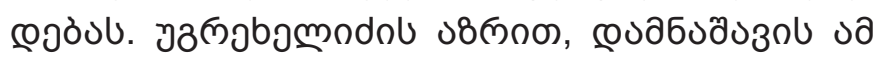

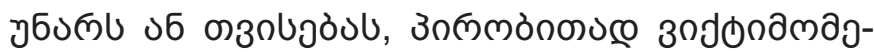

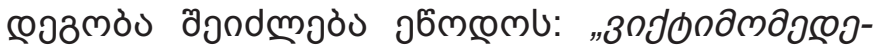

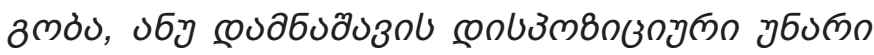

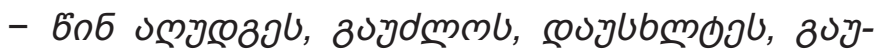

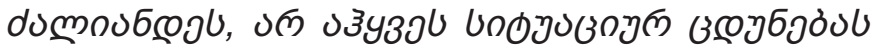

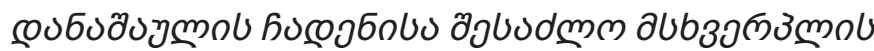

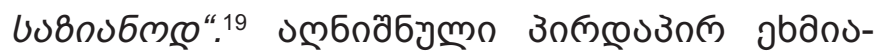

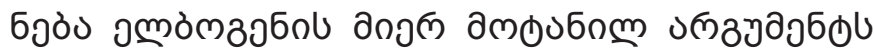

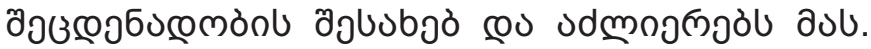

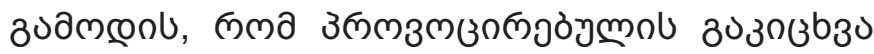

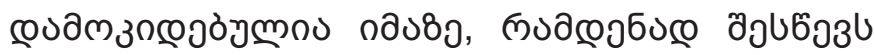

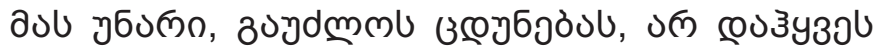

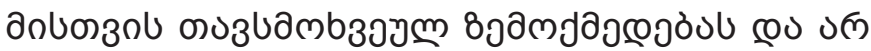

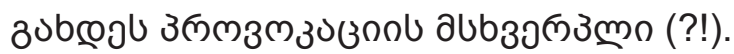

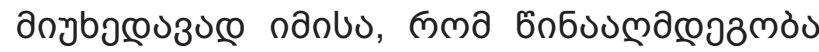

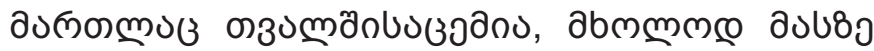

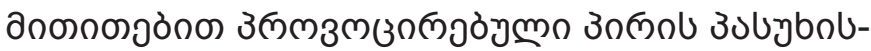

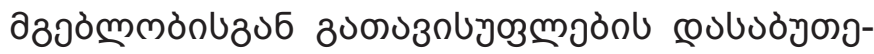

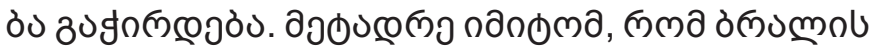

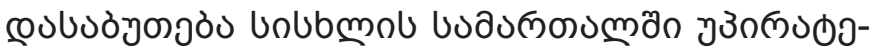

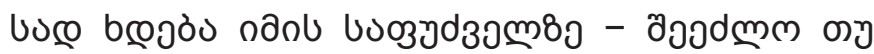

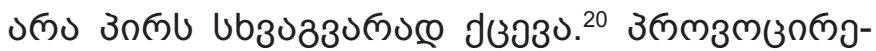

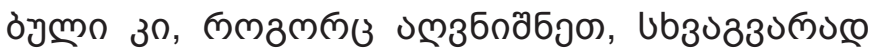

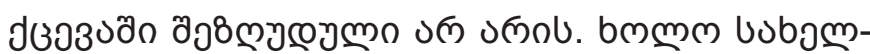

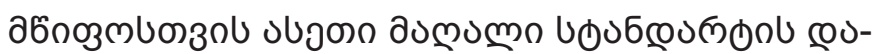

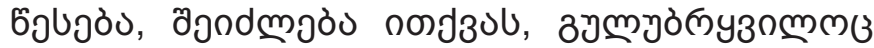

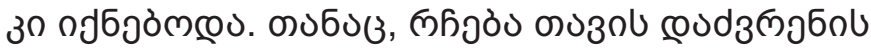

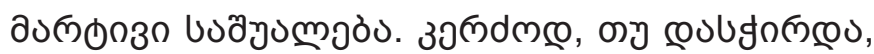

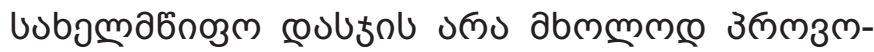

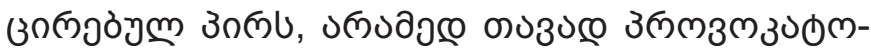

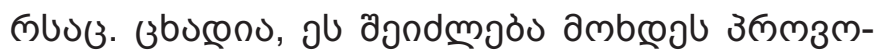

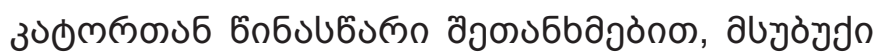

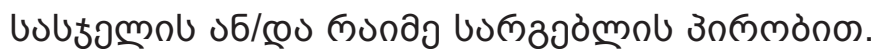

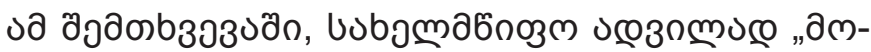

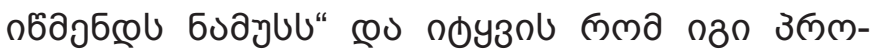

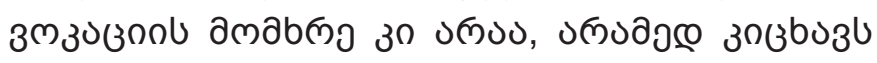

\footnotetext{
19 of3ง, 33. 24-26.

20 Ugrekhelidze, M., 1984. Die Bedeutung des Schuldgehalts der Tat im Strafrecht. Zweites Deutsch-Sowjetisches Kolloquium über Strafrecht und Kriminologie. BadenBaden: Nomos Verlags-Gesellschaft, S. 113-122.
} 


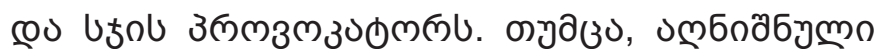

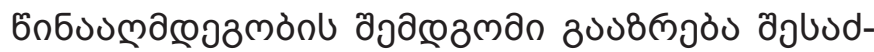

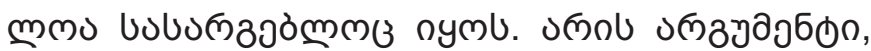

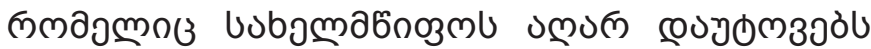

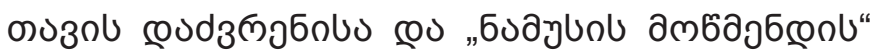

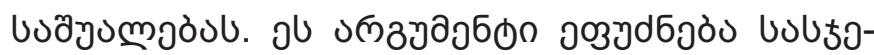

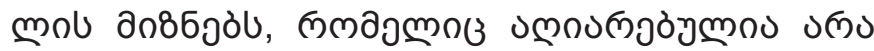

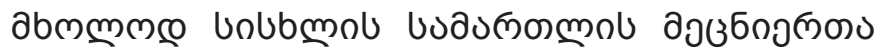

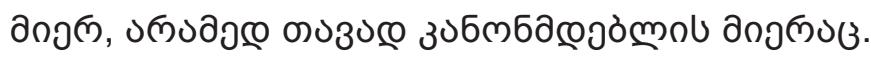

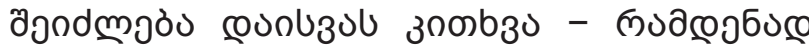

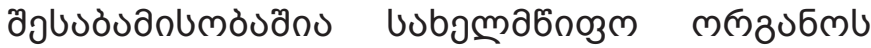

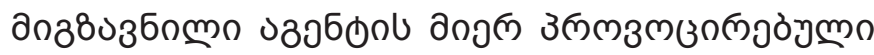

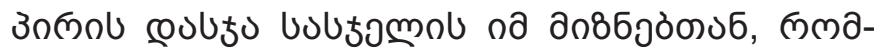

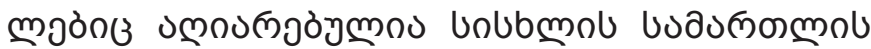

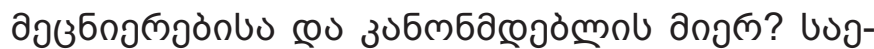

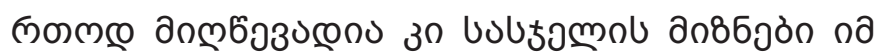

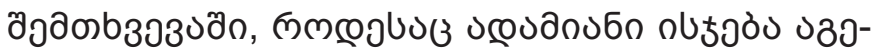

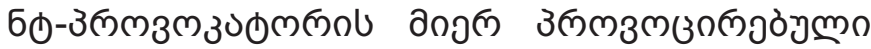

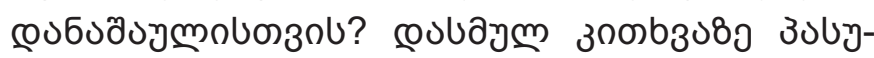

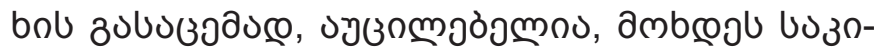

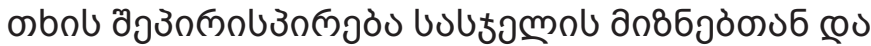

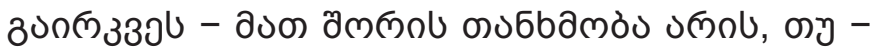
6оболмақоламы.

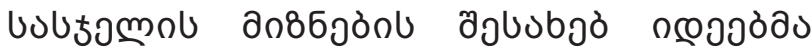

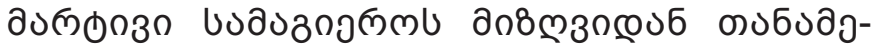

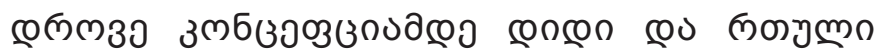

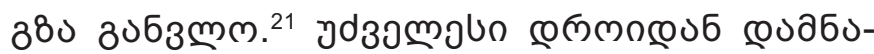

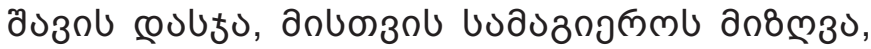

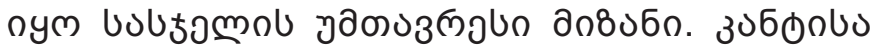

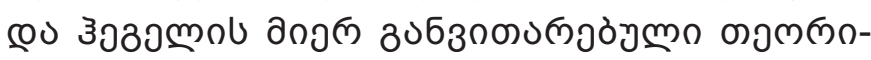

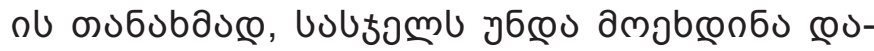

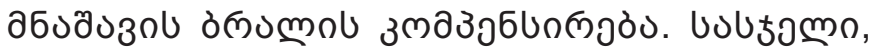

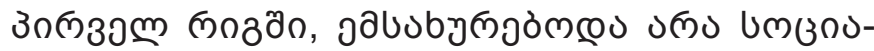

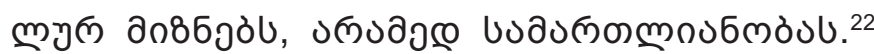

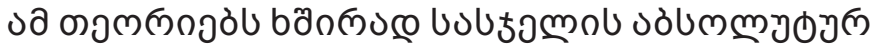

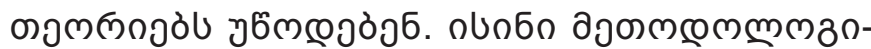

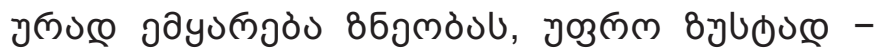

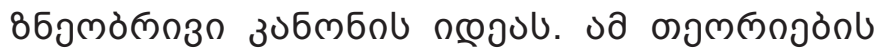

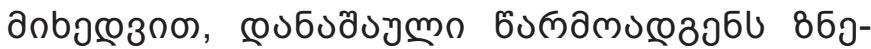

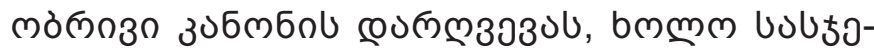

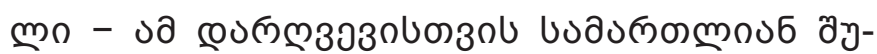

21

3 Strafrechtstheorieen in ihrem Verhältnisse zu einander und zu dem positiven Rechte und dessen Geschichte. Erster Theil. Philosophisch-historische Entwicklung des Begriffs von Verbrechen und Strafen. Frankfurt/Main: Verlag Sauer \& Auvermann KG, S. 8-73.

22 Roxin, Arzt, Tiedemann. 2013. Einführung in das Strafrecht und Strafprozessrecht. 6 Auflage. C. F. Müller, S. 4-5.

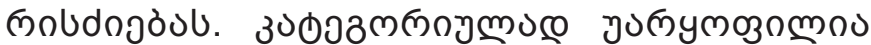

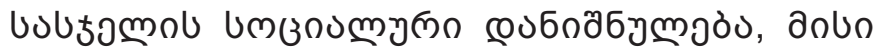

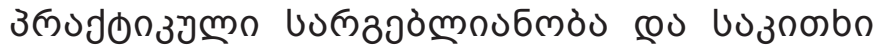

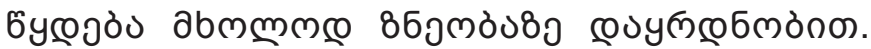

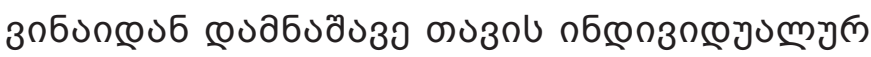

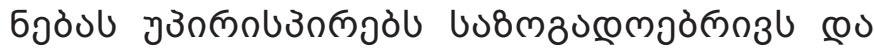

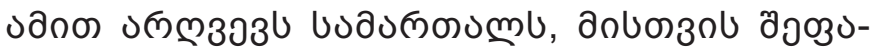

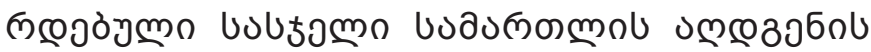

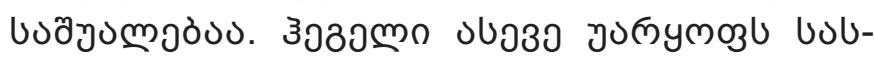

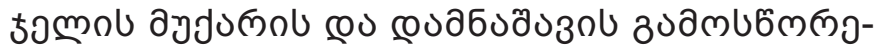

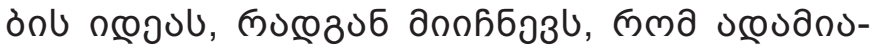

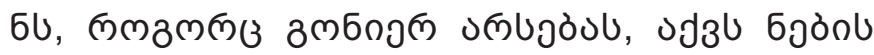

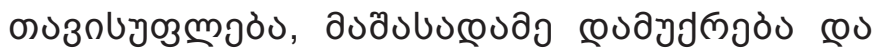

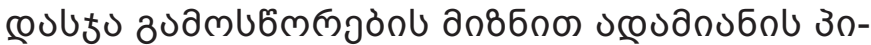

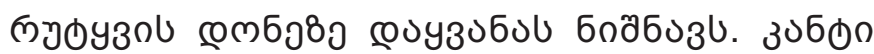

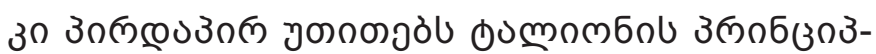

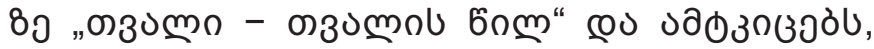

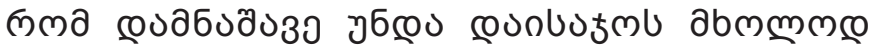

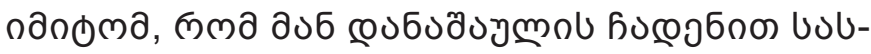

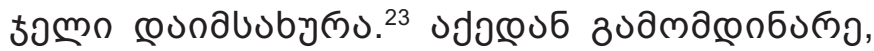

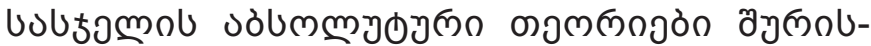

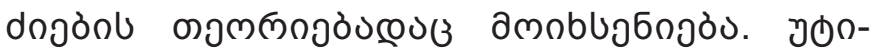

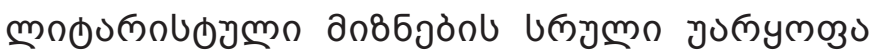

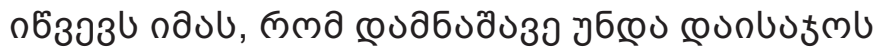

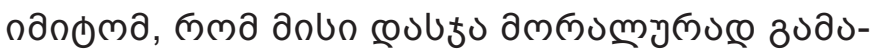

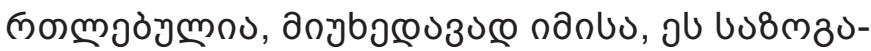

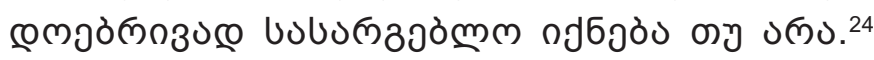

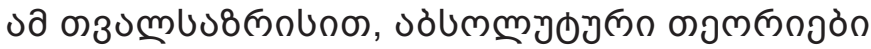

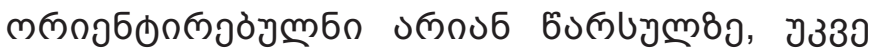
амabsoum оु०J080. ${ }^{25}$

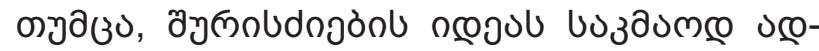

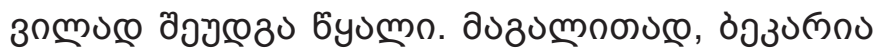

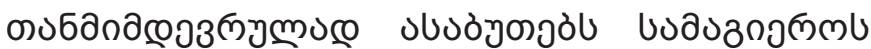

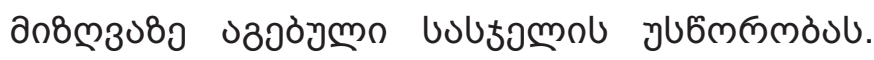

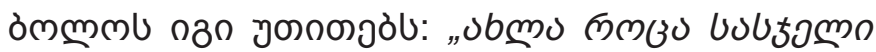

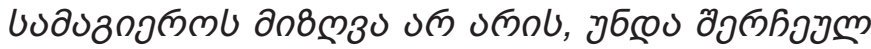

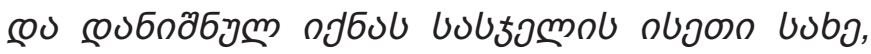

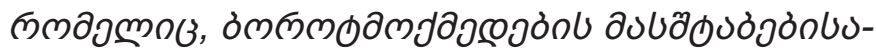

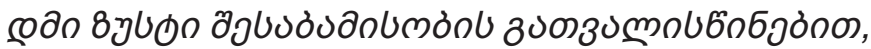

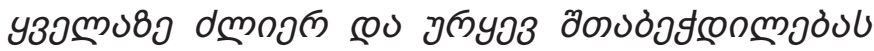

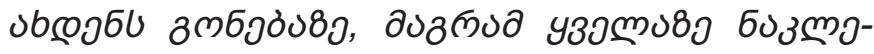

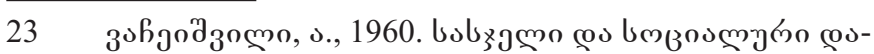

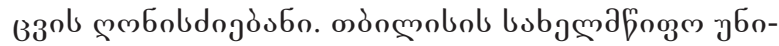

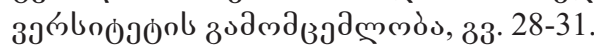

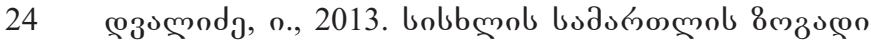

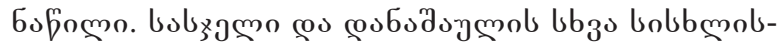

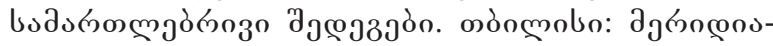
Бо, 33.18.

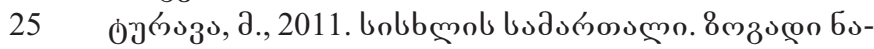

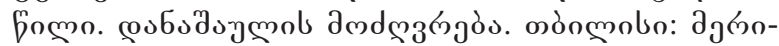
cos6o, 33. 42-43. 


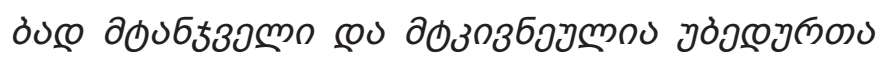

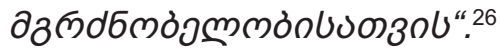

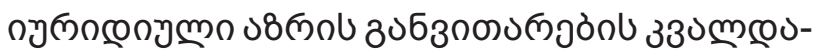

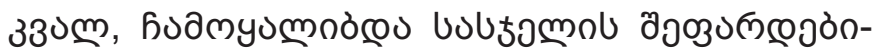

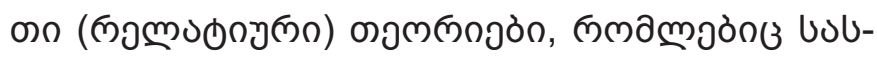

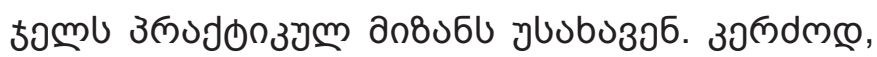

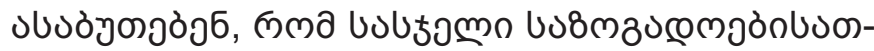

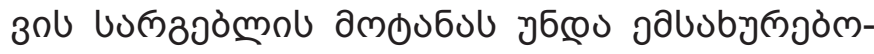

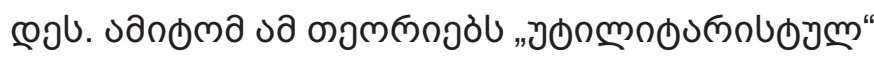

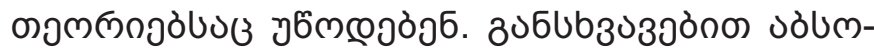

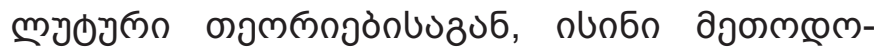

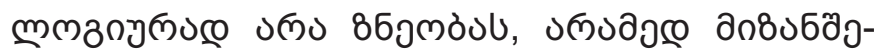

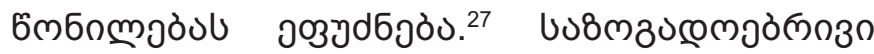

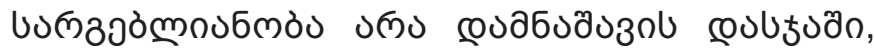
১๓

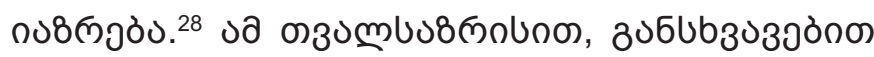

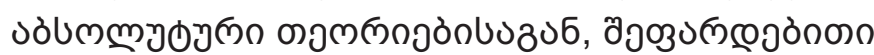

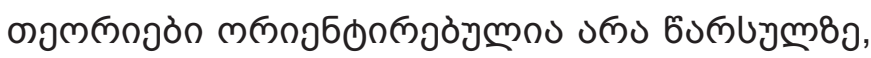

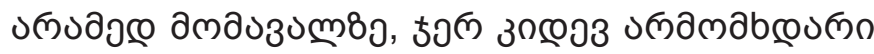

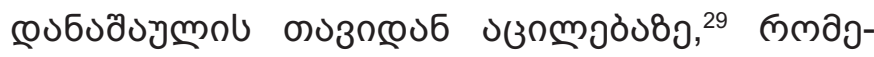

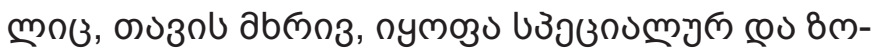

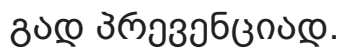

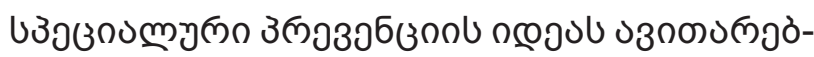

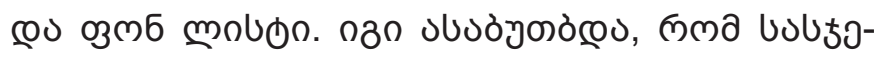

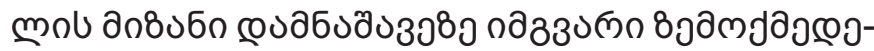

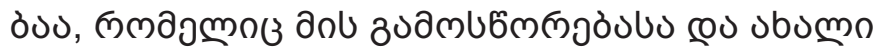

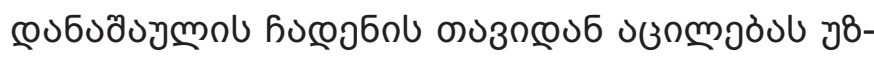

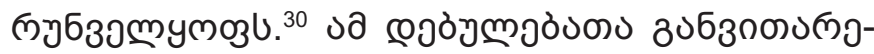

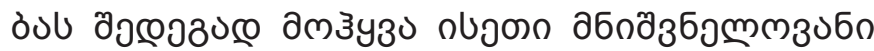

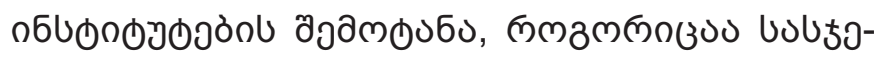

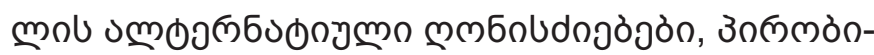
๓n ab5uз

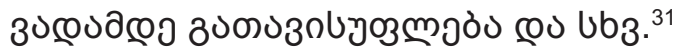

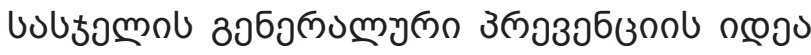

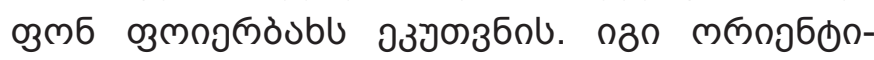

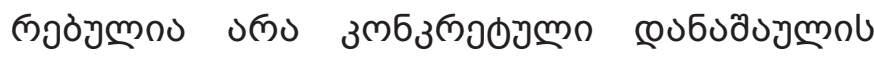

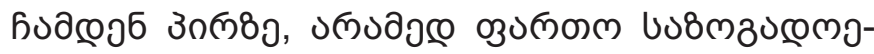

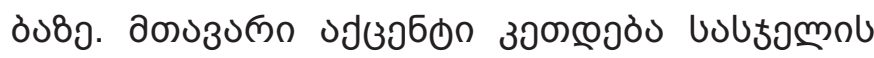

26 Beccaria, C., 1764. Von Verbrechen und Strafen. Auf das neue selbst aus dem Italienischen übersetzt mit durchgängigen Anmerkungen des Ordinarius zu Leipzig. Breslau, S. 67.

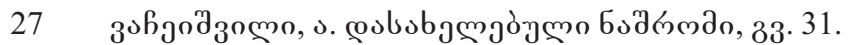

28 Grolman, K., 1968. Über die Begründung des Strafrechts und der Strafgesetzgebung. Frankfurt am Main: Verlag Sauer \& Auvermann KG, S. 56.

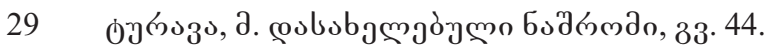

30 Von Liszt F. 1905. Strafrechtliche Aufsätze und Vorträge. Der Zweckgedanke im Strafrecht. Erster Band. Berlin: J. Guttentag Verlagsbuchhandlung G.m.b.H., S. 163-179.

31

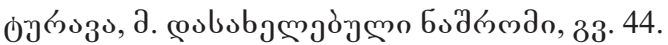

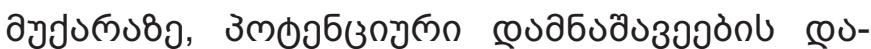

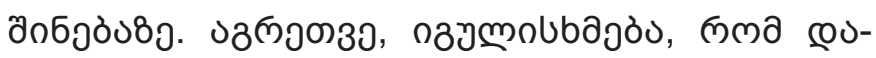

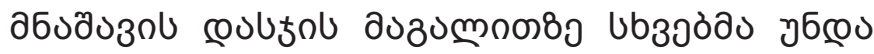

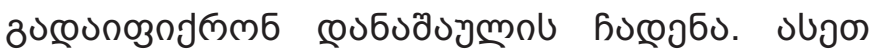

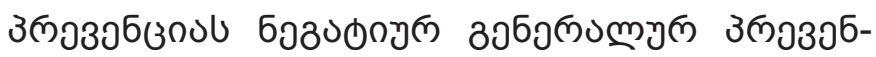

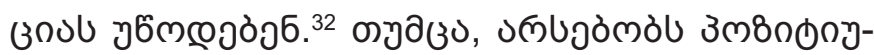

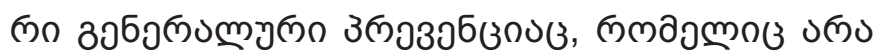

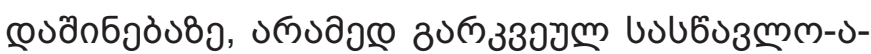

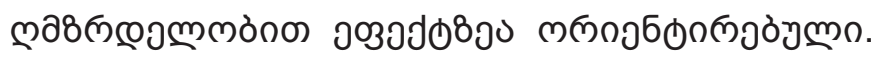

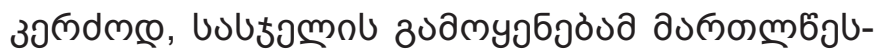

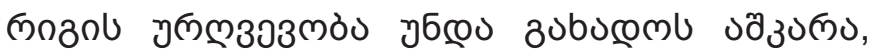

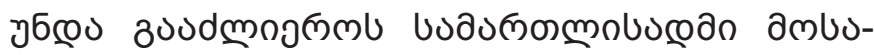

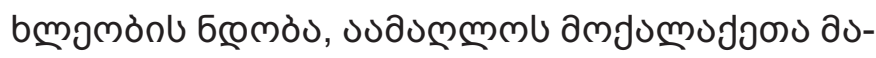

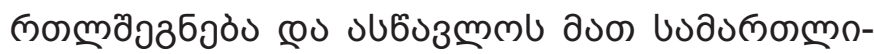

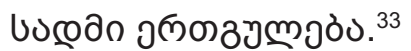

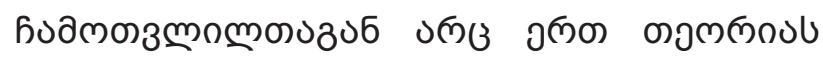

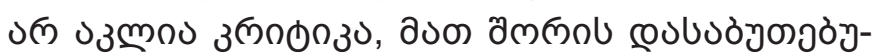

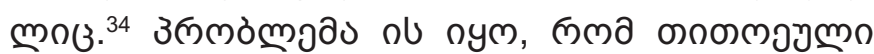

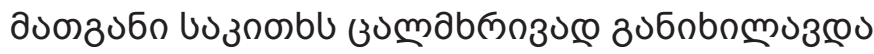

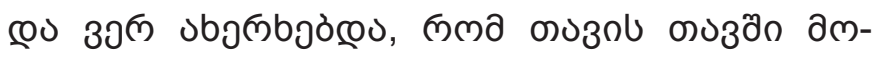

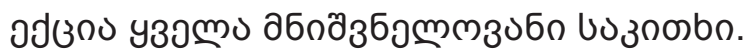

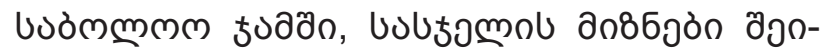

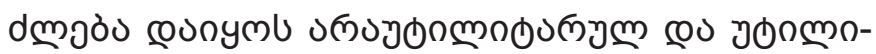

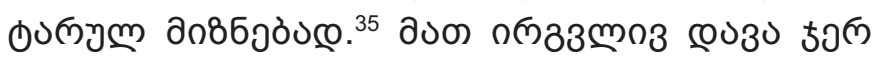

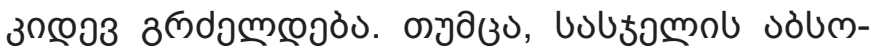

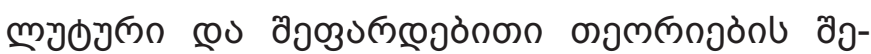

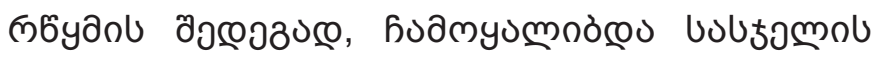

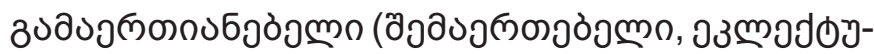

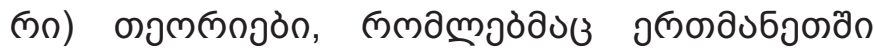

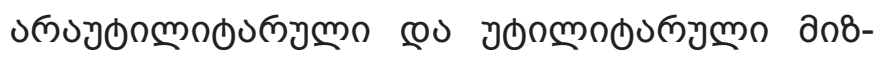

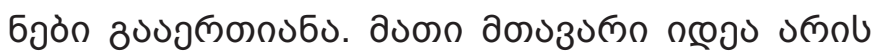

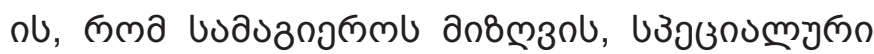

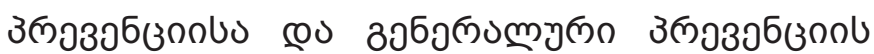

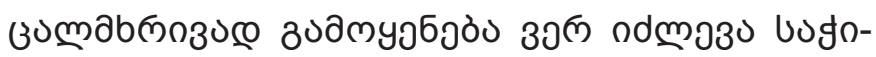

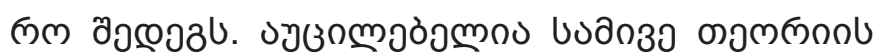

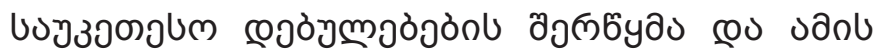

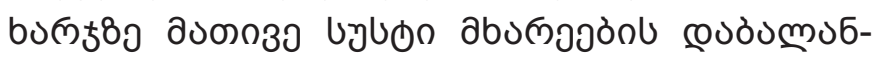

32 Von Feuerbach P.J.A.R. 1798. Ist Sicherung vor dem Verbrechen Zweck der Strafe und ist Strafrecht Präventionsrecht. Bibliothek für die peinliche Rechtswissenschaft und Gesetzkunde.

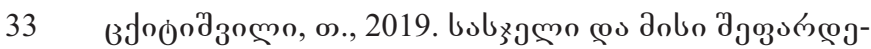

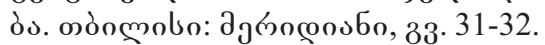

34 Köstlin, C.R., 1978. System des deutschen Strafrechts. Allgemeiner Teil. Erste Abteilung. Neudruck der Ausgabe. Tübingen: Scientia Verlag Aalen, S. 395-413.

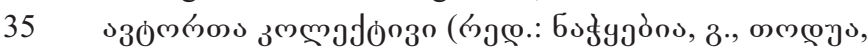

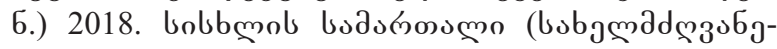

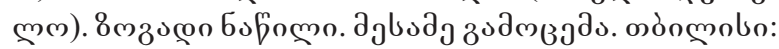

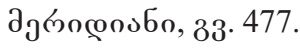




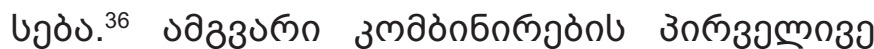

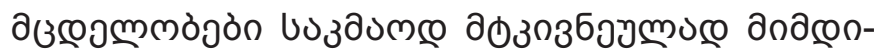

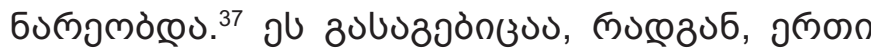

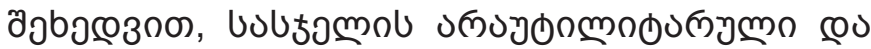

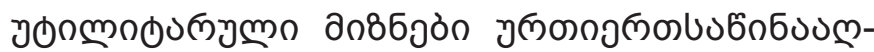

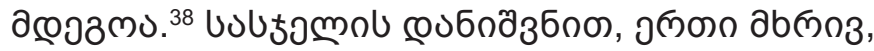

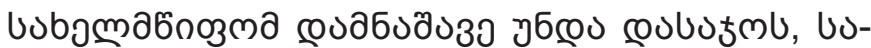

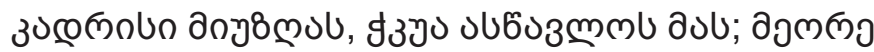

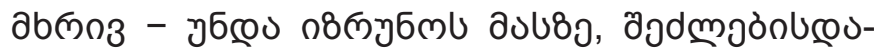

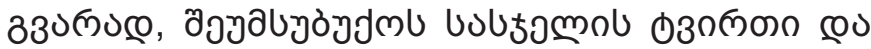

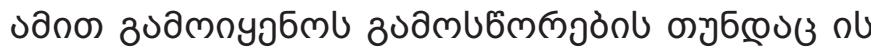

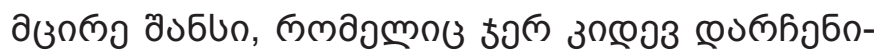

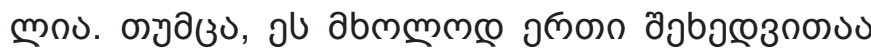

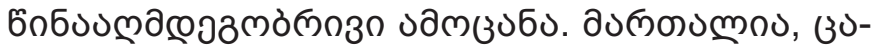

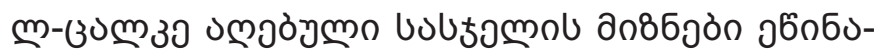

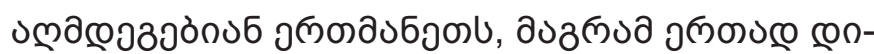

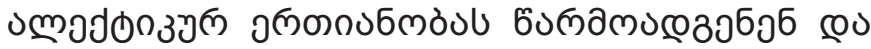

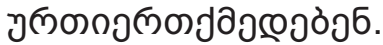

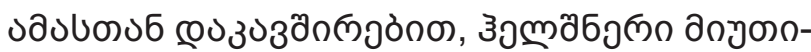

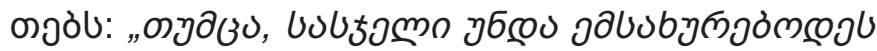

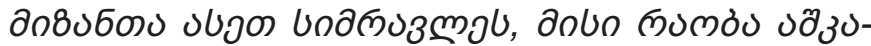

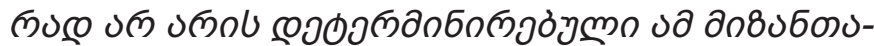

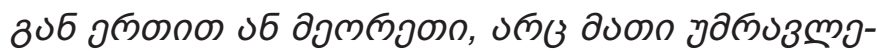

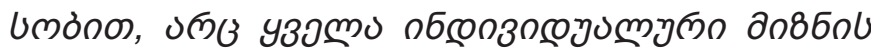

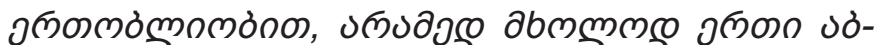

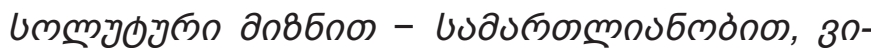

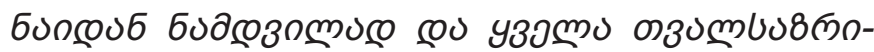

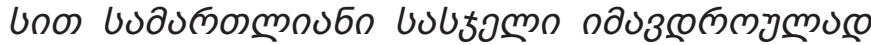

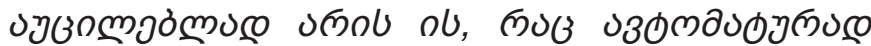

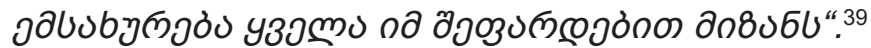

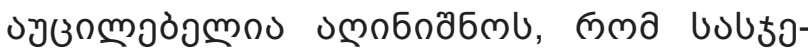

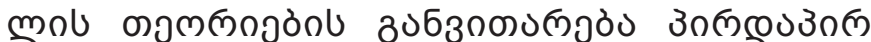

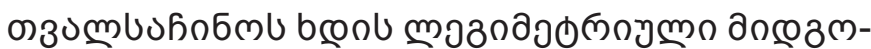

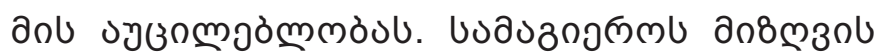

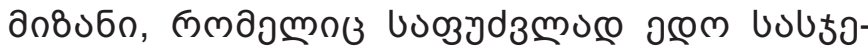

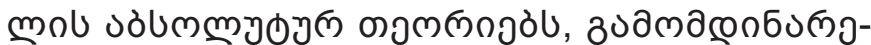

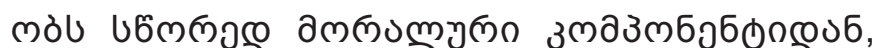

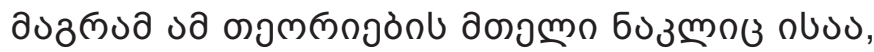

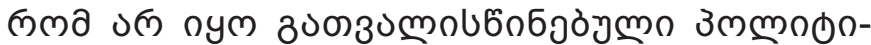

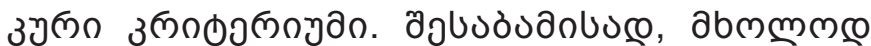

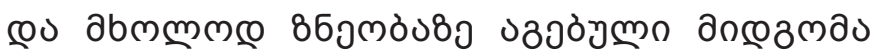

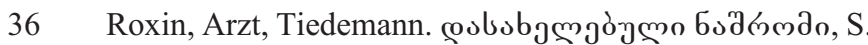
6-7.

37 Von Bar C. L. 1882. Handbuch des Deutschen Strafrechts. Erster Band. Geschichte des Deutschen Strafrechts und der Strafrechtstheorien. Berlin: Weidmannsche Buchhandlung, §. 95. S. 270-273.

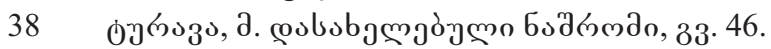

39 Hälschner, H., 1858. Das preußische StrafrechtSystem des preußischen Strafrechts Zweiter Theil oder allgemeiner Theil des Systems. bei Adolph Marcus. Bonn. S., 440.

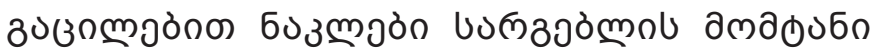

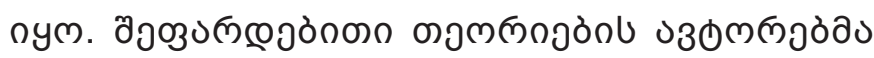

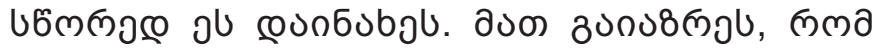

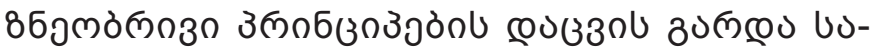

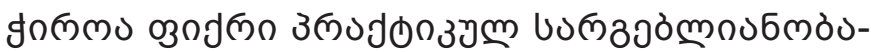

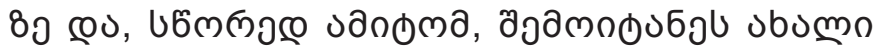

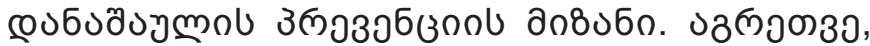

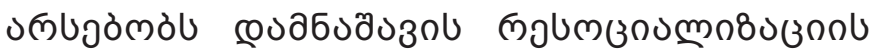

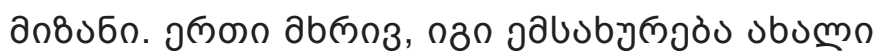

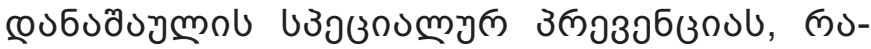

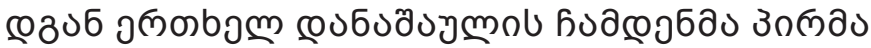

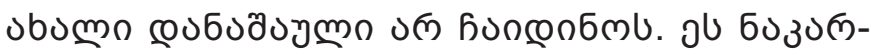

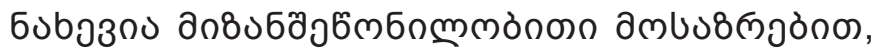

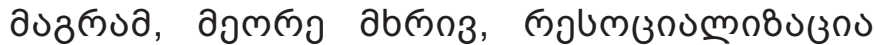

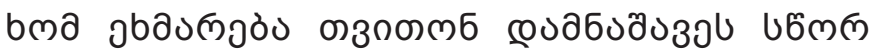

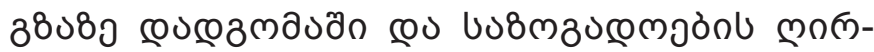

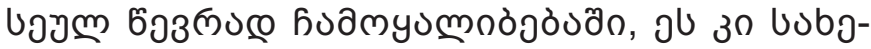

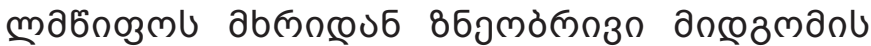

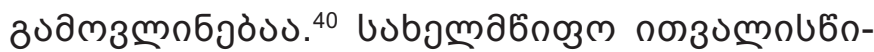

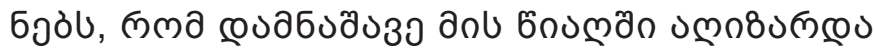

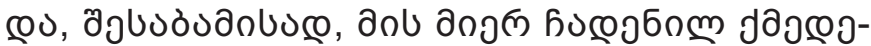

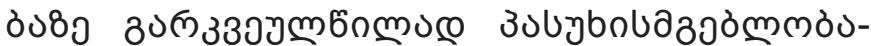

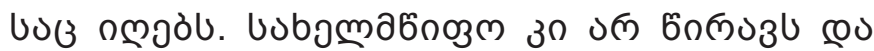

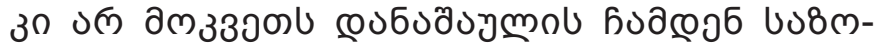

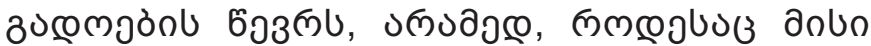

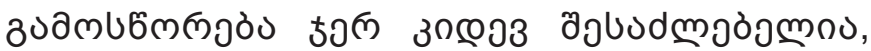

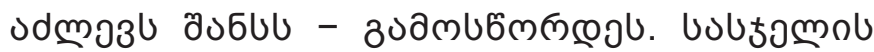

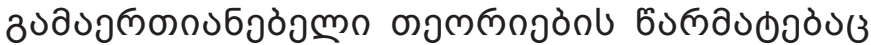

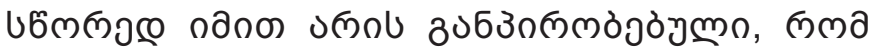
০

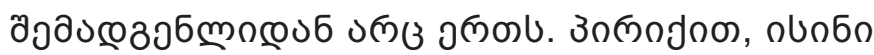

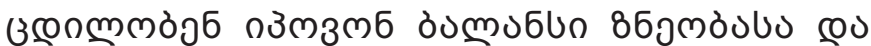

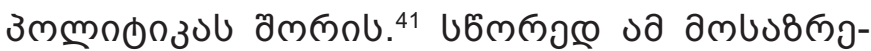

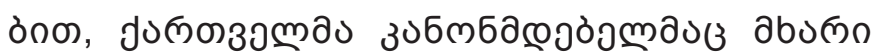

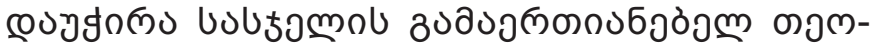

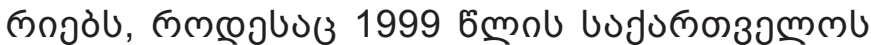
unbbmol usaummmol зmณodunb 39-0 ay-

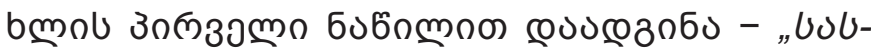

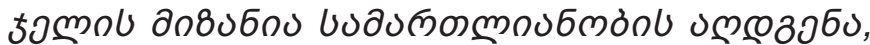

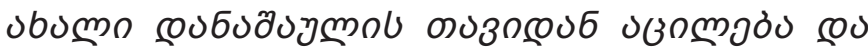

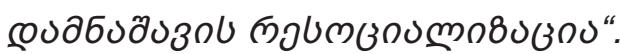

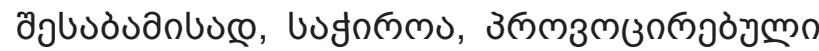

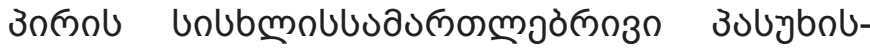

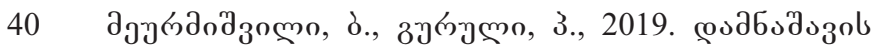

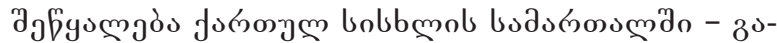

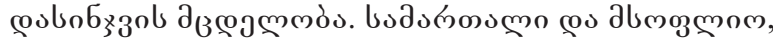
№11, 33.22.

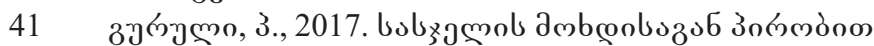

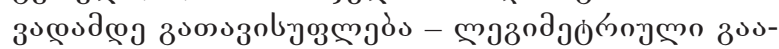

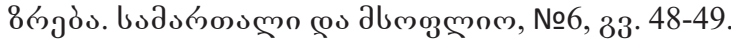




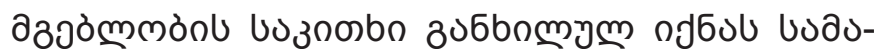

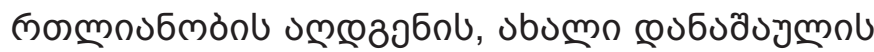

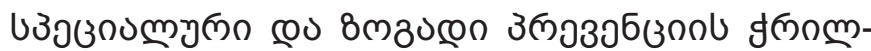

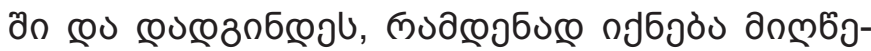
उง

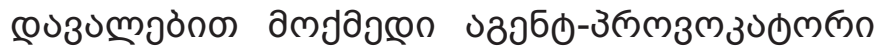

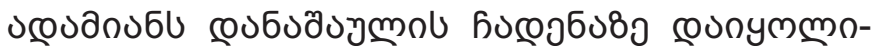

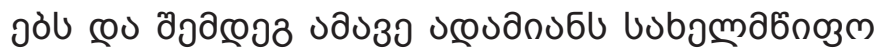

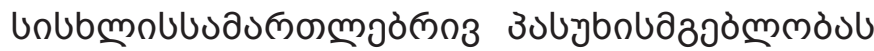
çoงzoungòl.

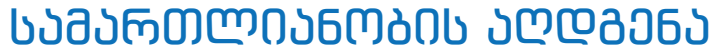

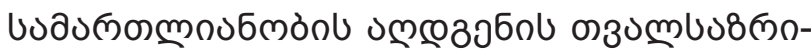

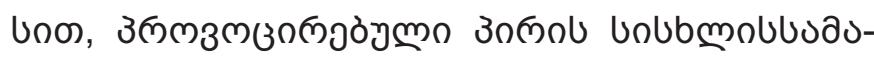

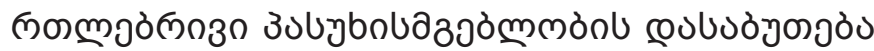

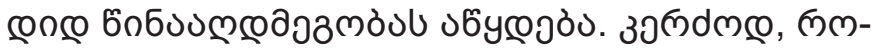

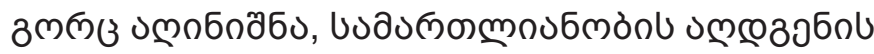

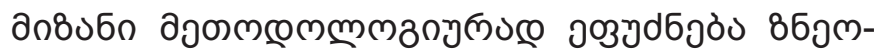

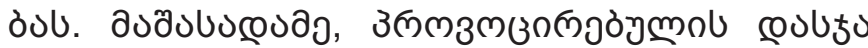

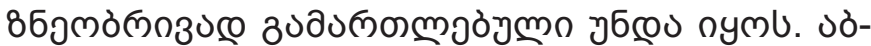

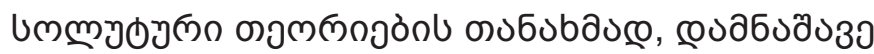

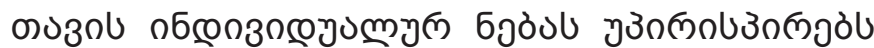

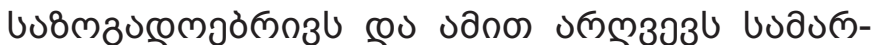

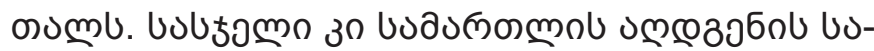

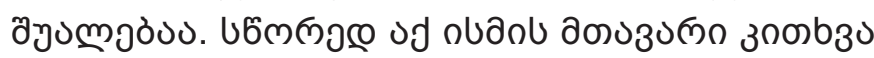

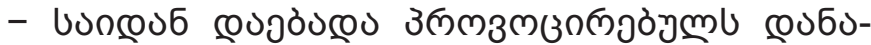

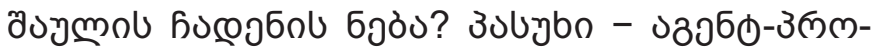

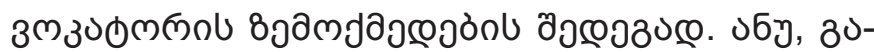

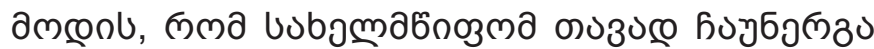

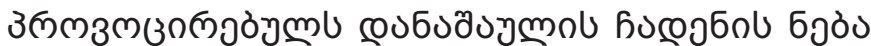

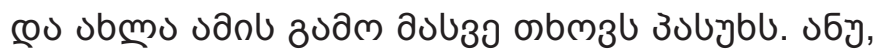

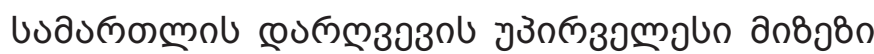

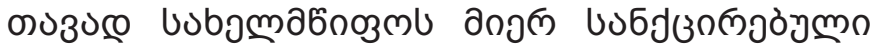

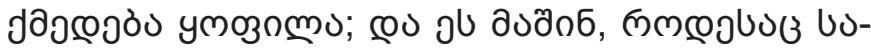

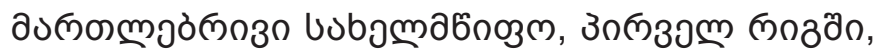

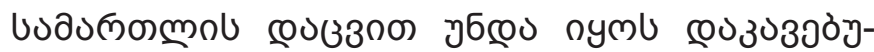

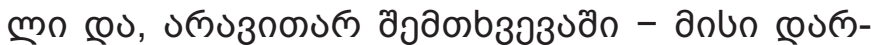

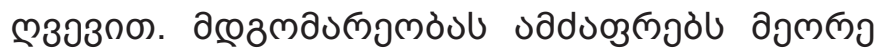

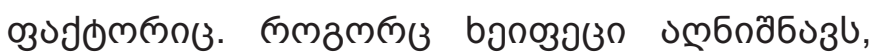

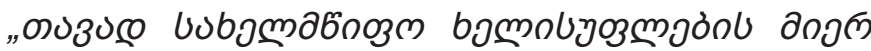

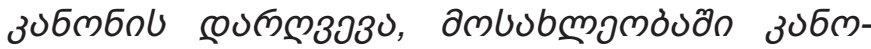

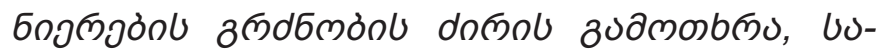

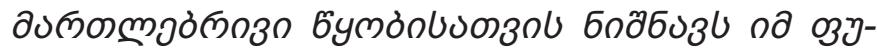

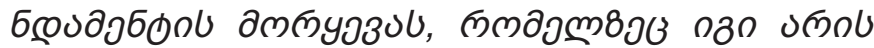

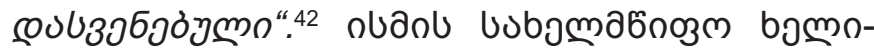

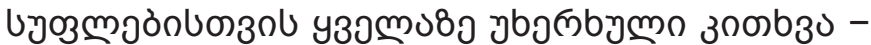

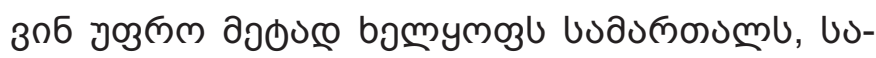

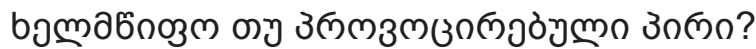

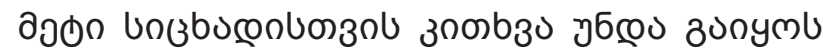

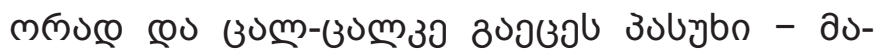

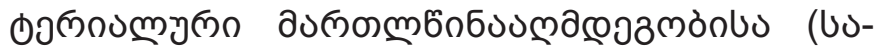

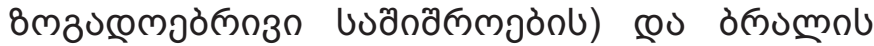

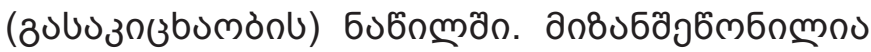

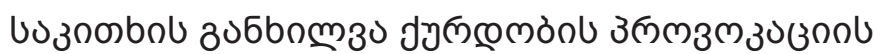

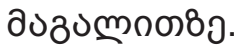

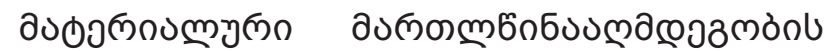

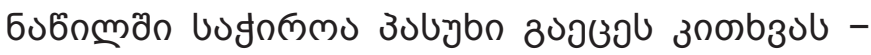

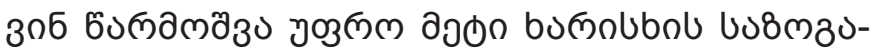

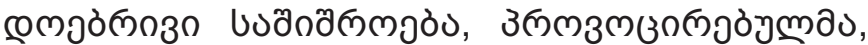

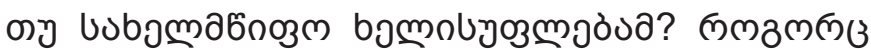

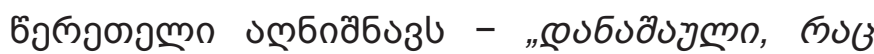

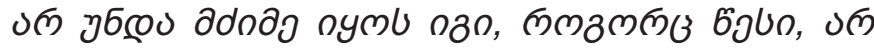

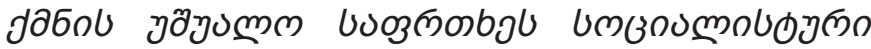

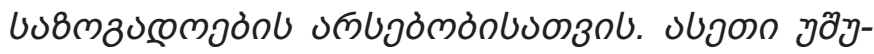

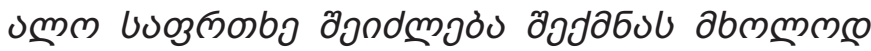

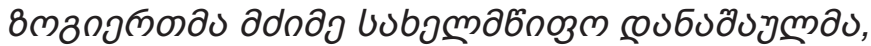

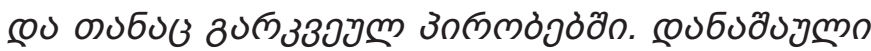

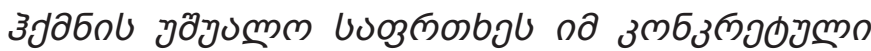

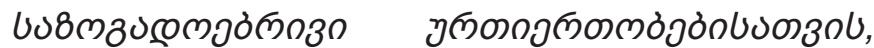

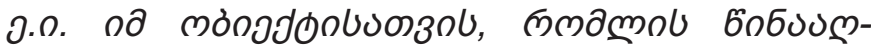
дূ0

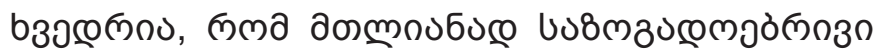

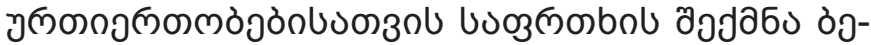

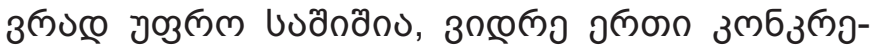

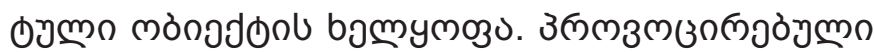

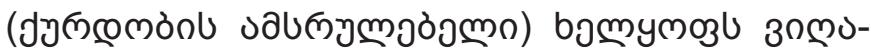

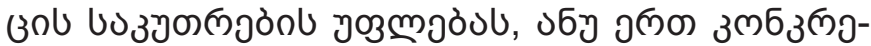

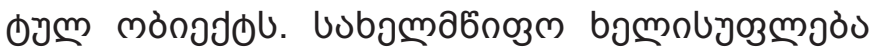

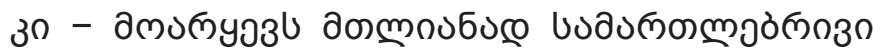

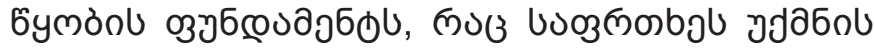

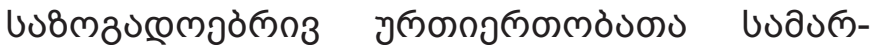

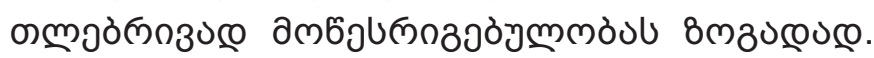

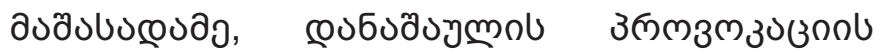

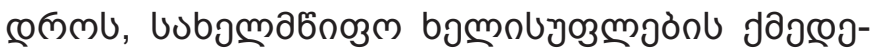

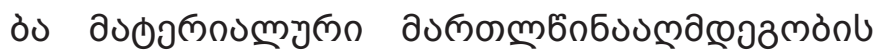

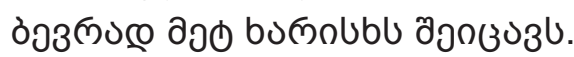

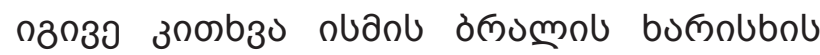

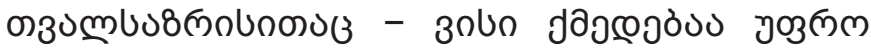

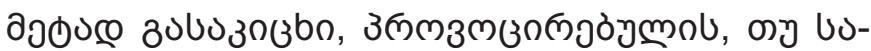

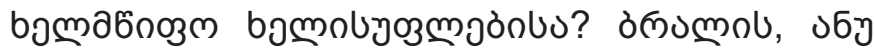

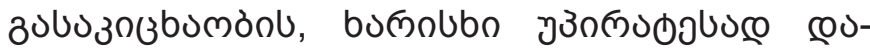

«ПравовьдБнІЕ» И. К. Голубева, стр. 127.

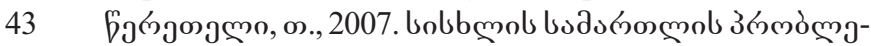

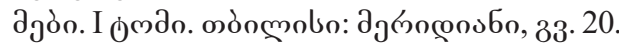




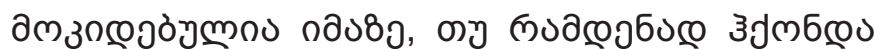

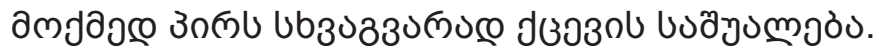

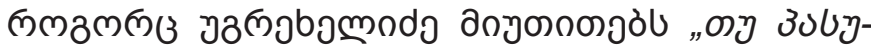

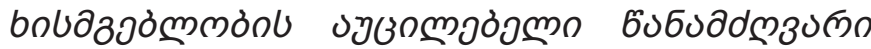

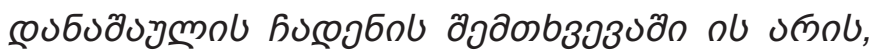

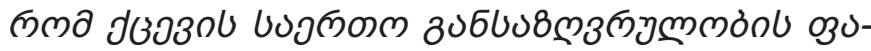

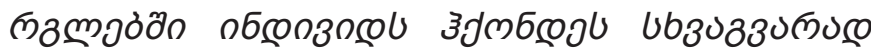

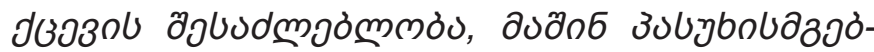

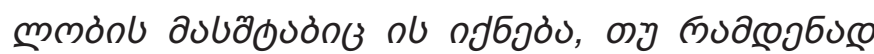

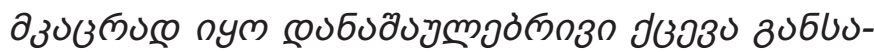

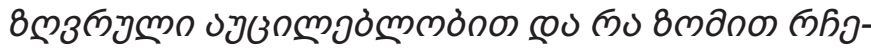

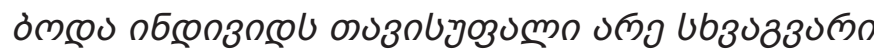

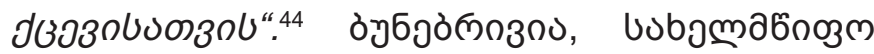

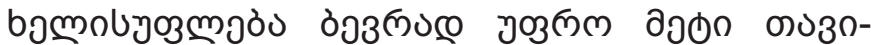

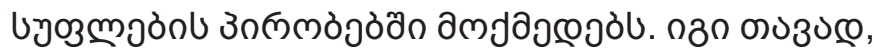

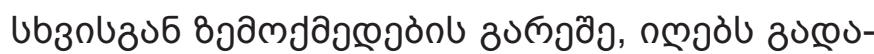

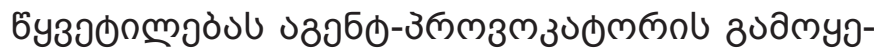

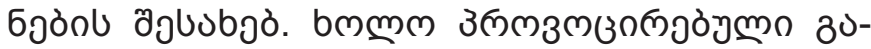

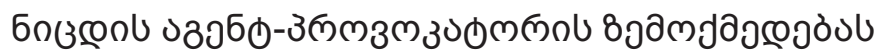

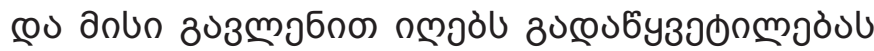

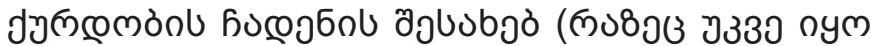

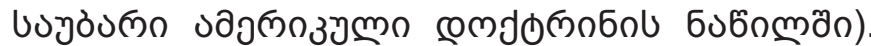

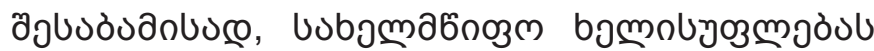

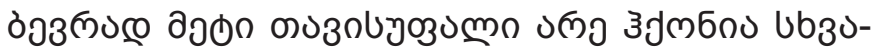

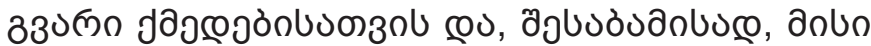

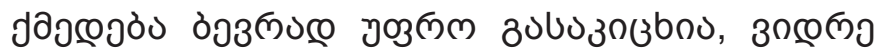

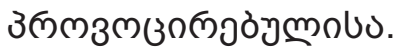

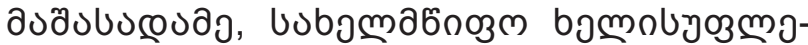

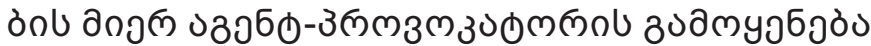

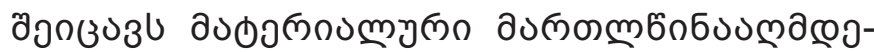

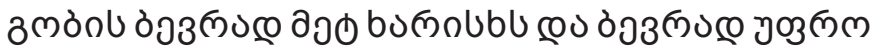

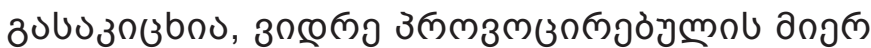

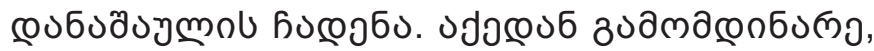

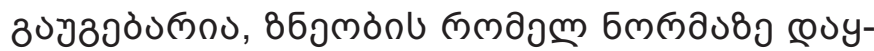

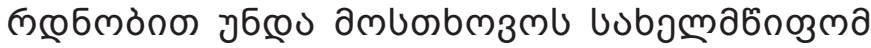

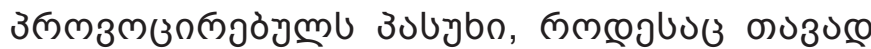

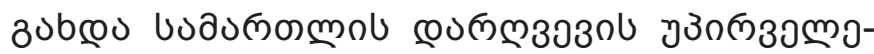

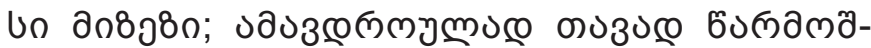

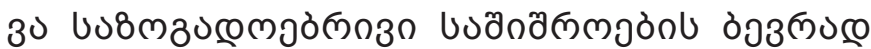

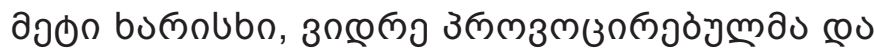

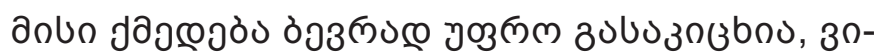

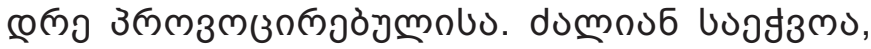

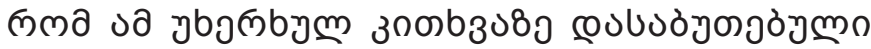

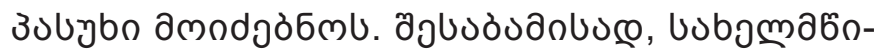

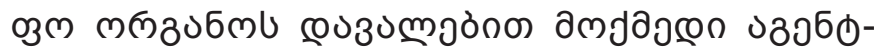

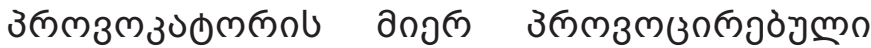

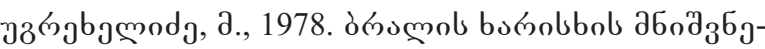

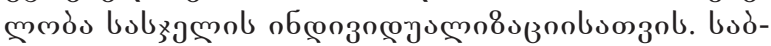

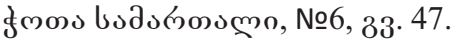

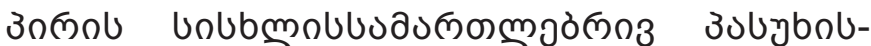

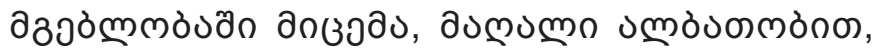

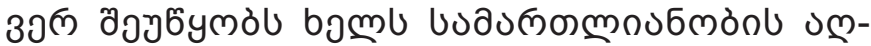
cosobul.

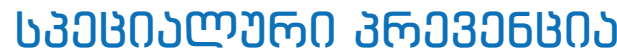

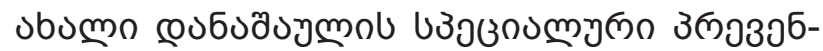

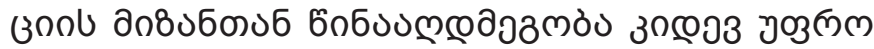

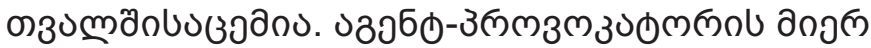

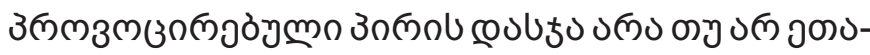

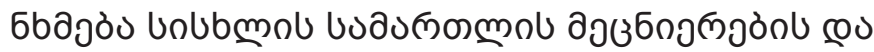

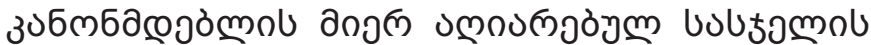

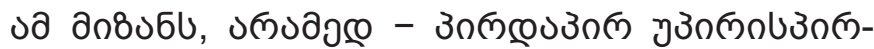

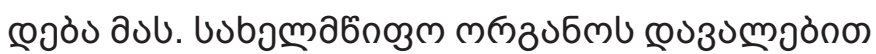

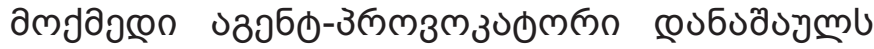

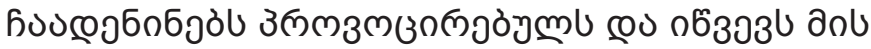

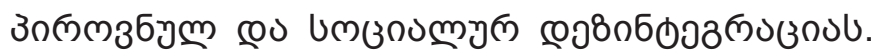

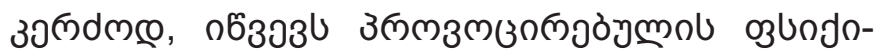

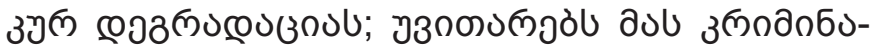

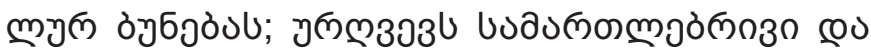

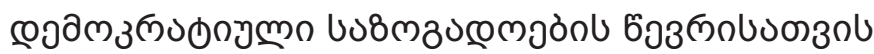

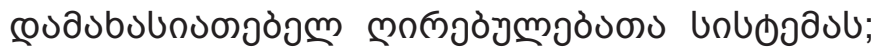

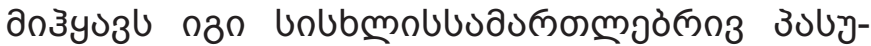

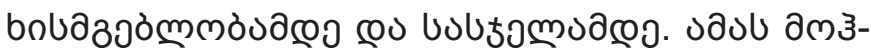

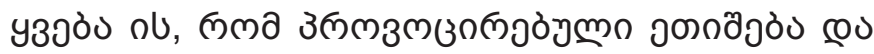

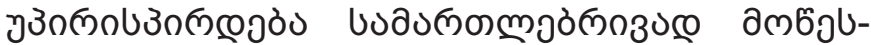

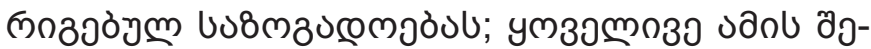

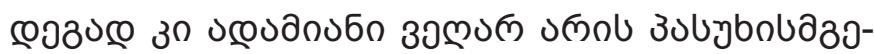

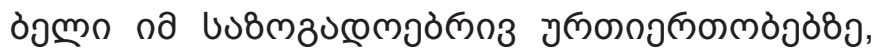

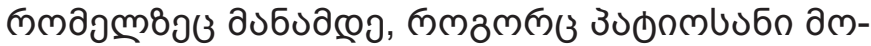

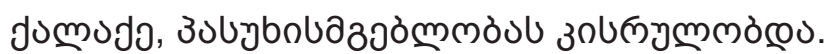

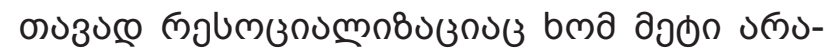

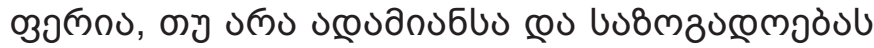

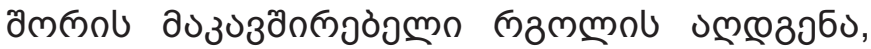

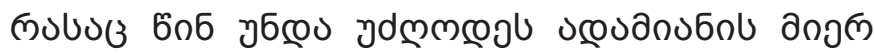

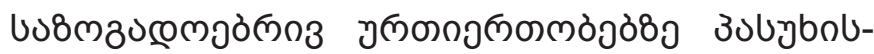

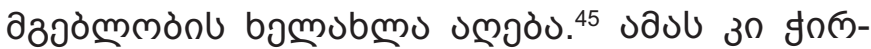

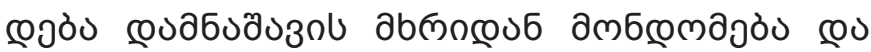

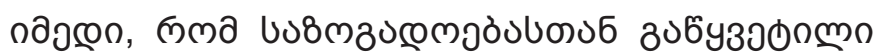

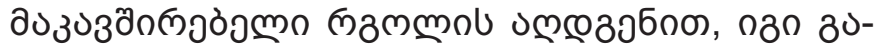

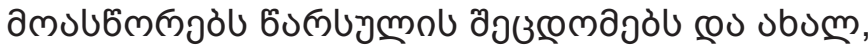

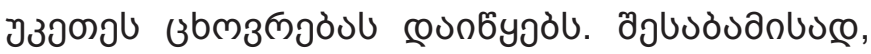

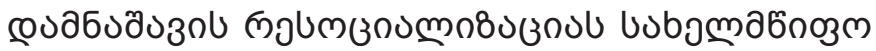

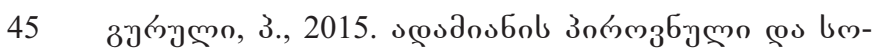

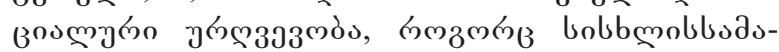

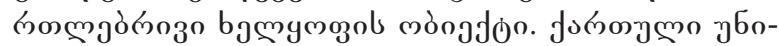

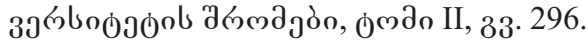




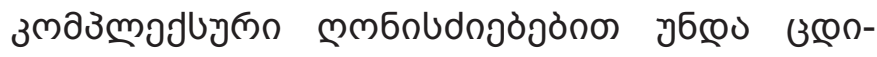
mmórogl. 46

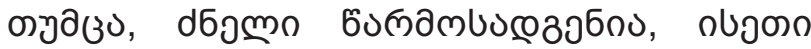

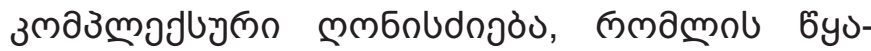

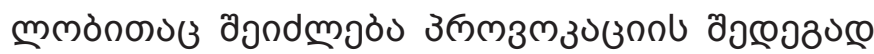

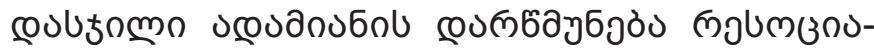

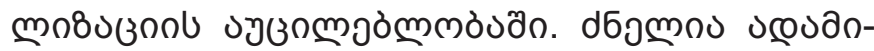

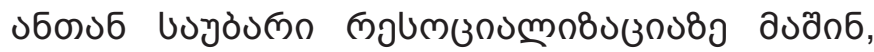

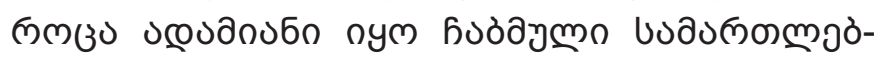

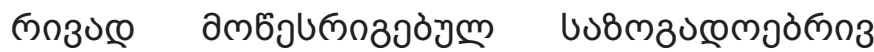

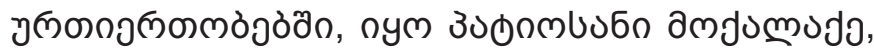

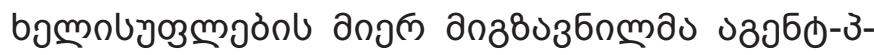

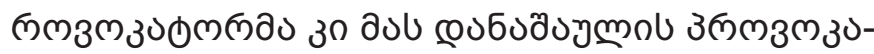

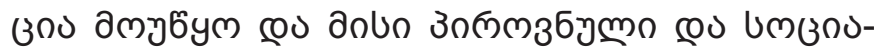

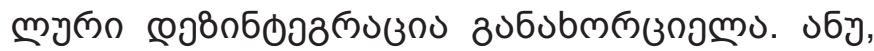

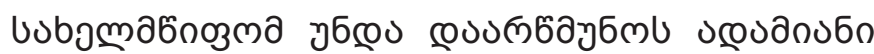

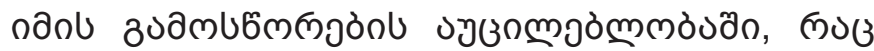

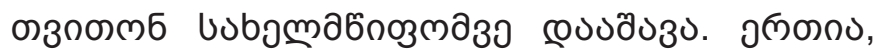

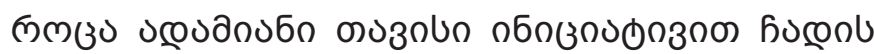

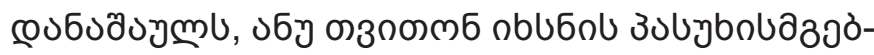

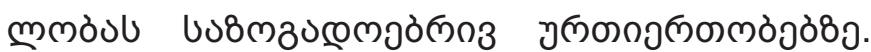

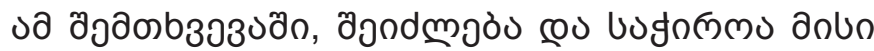

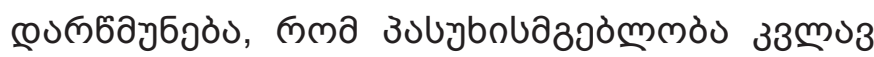

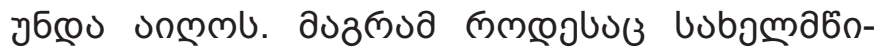

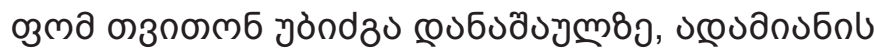

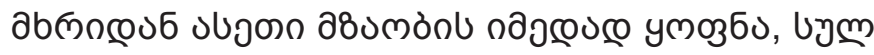

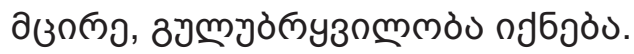

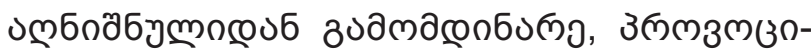

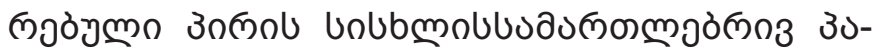

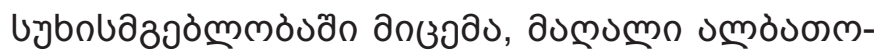

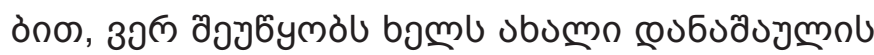

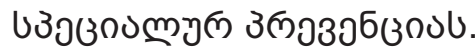

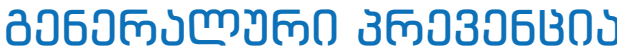

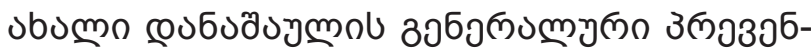

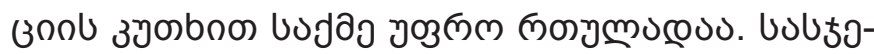

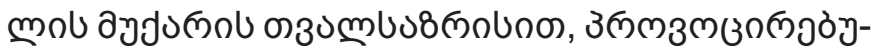

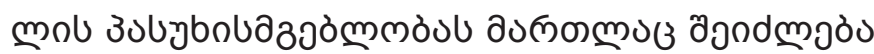

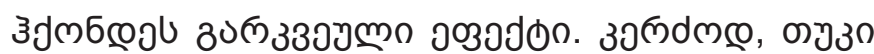

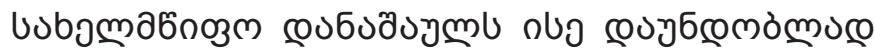

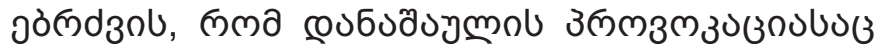

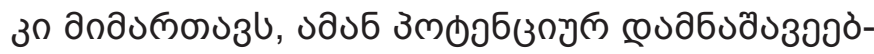

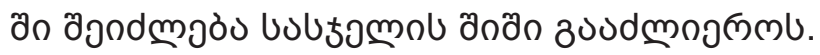

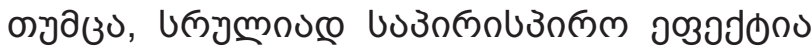

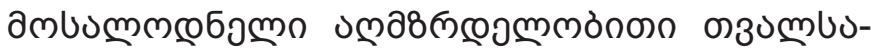
mo ... 33.30 .

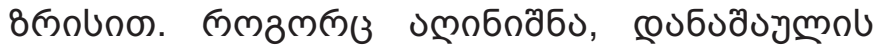

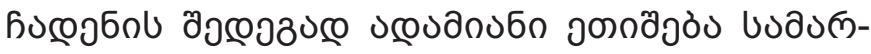

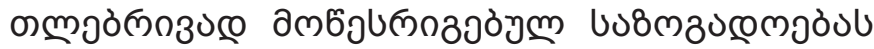

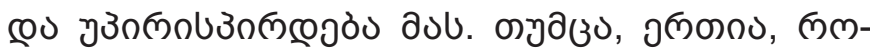

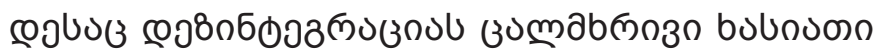

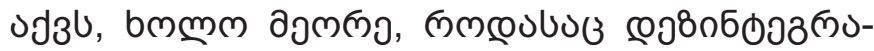

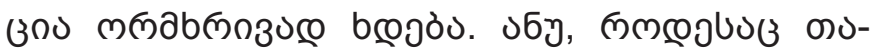

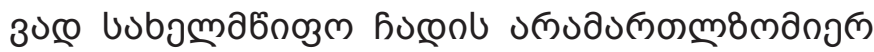

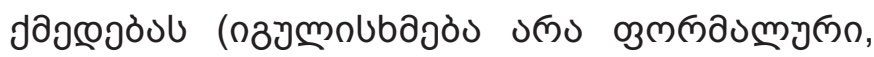

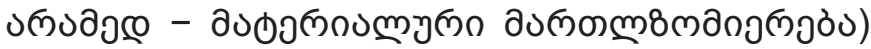

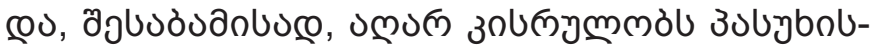

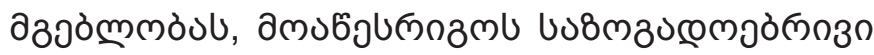

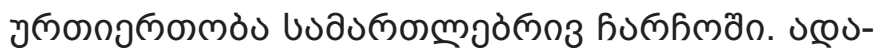

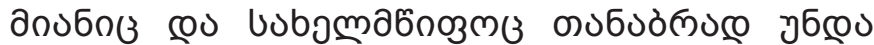

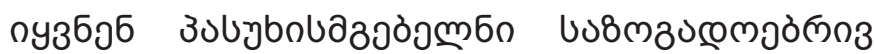

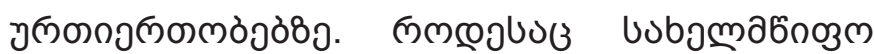

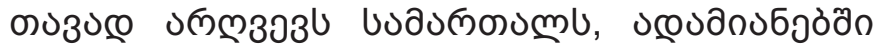

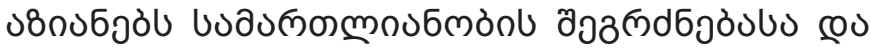

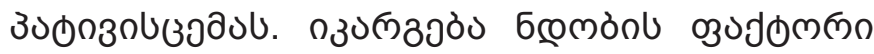

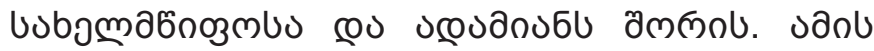

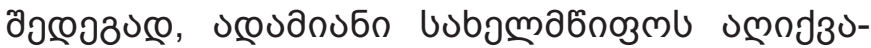

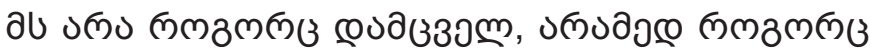

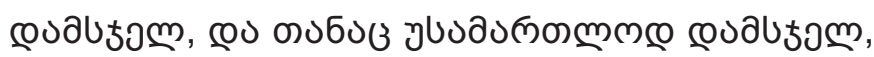

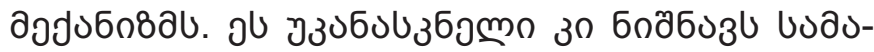

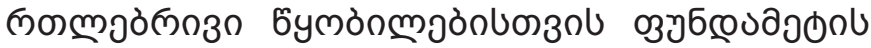
дмпучзо०. ${ }^{47}$

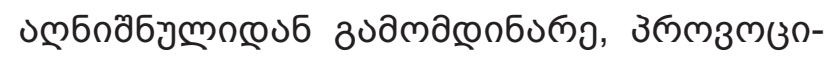

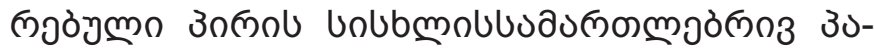

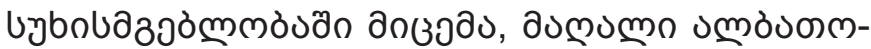

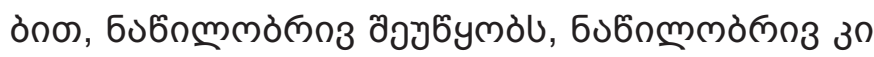

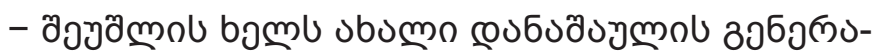

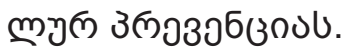

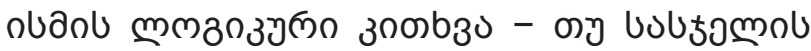

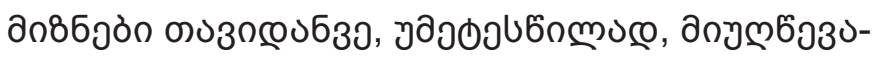

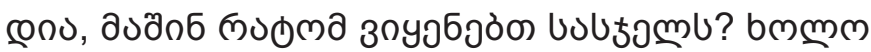

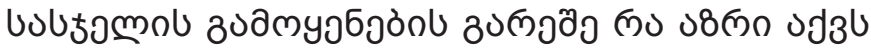

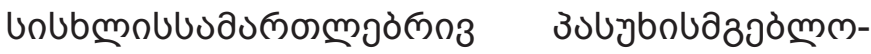

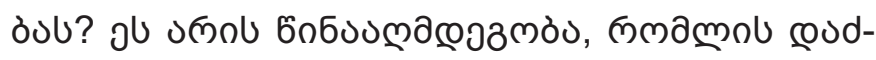

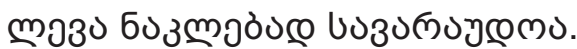

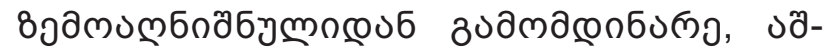

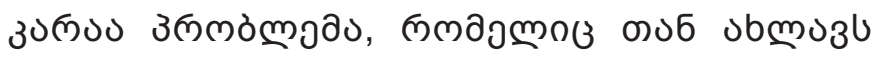

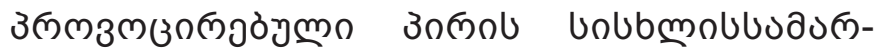

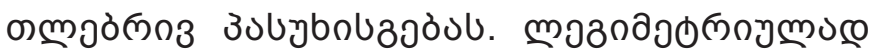

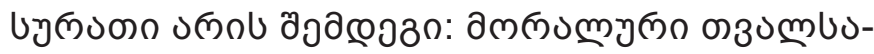

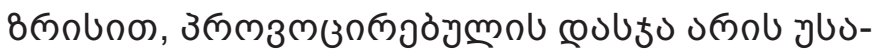

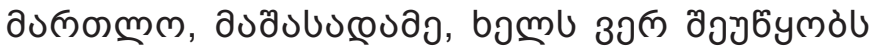

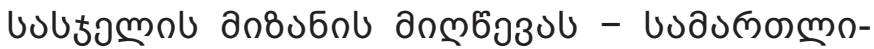

47

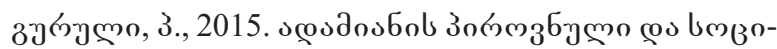

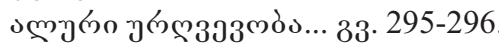




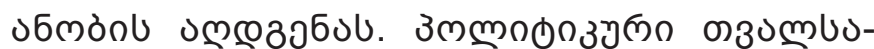

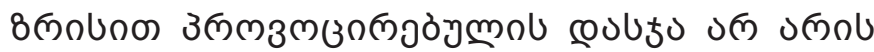

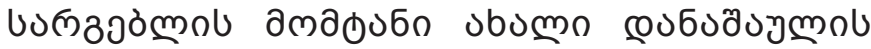

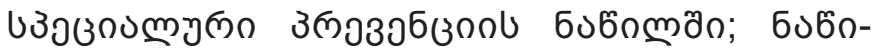

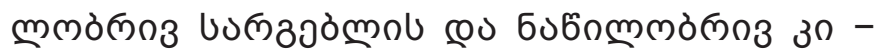

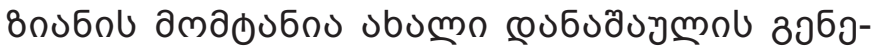

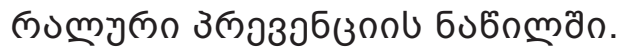

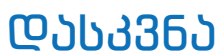

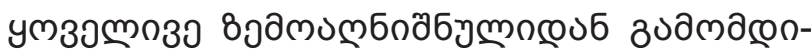

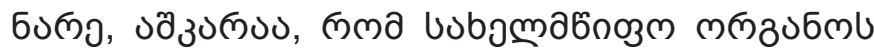

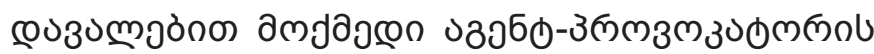

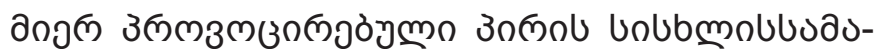

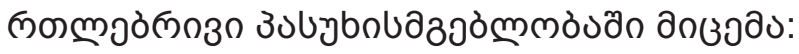

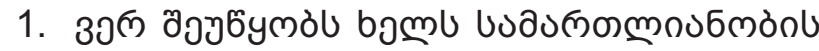

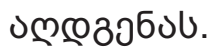

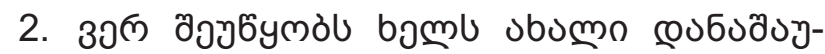

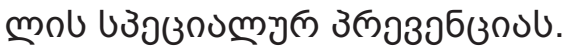

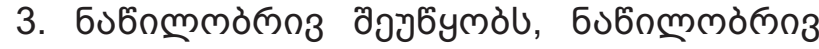

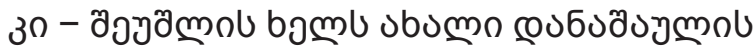

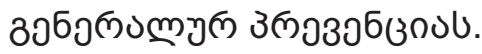

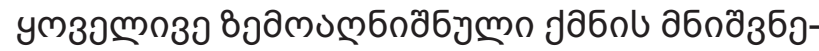

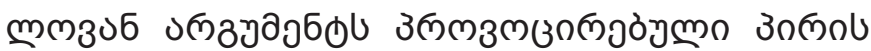

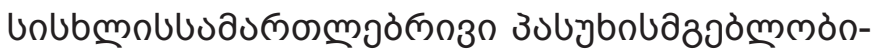

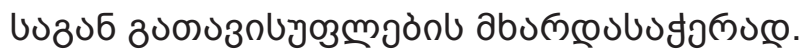

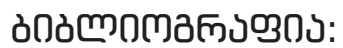

\section{பЈगЈलозомल:}

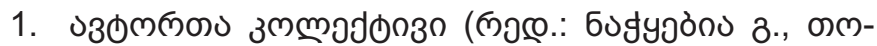

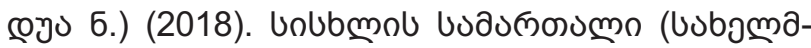

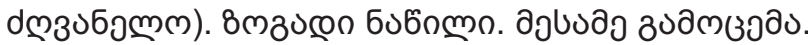

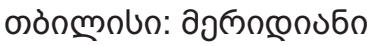

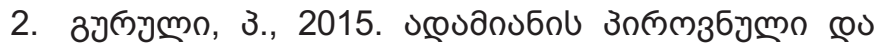

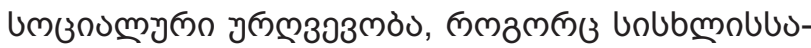

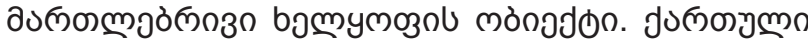

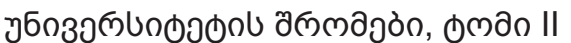

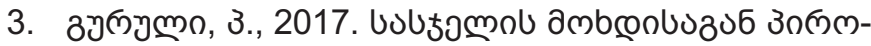

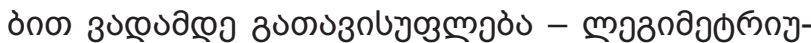

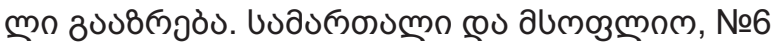

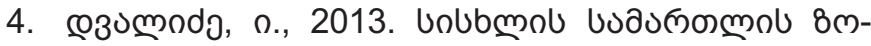

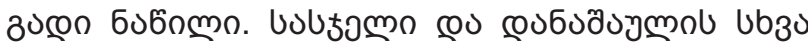

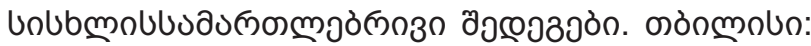

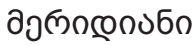

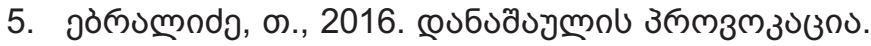

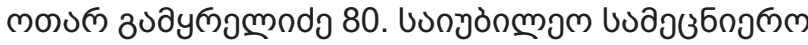

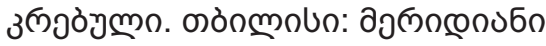

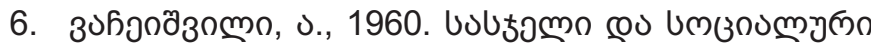

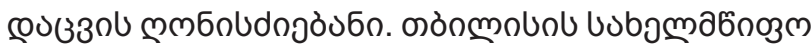

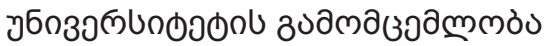

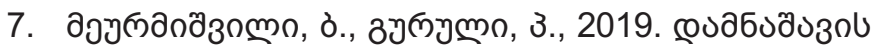

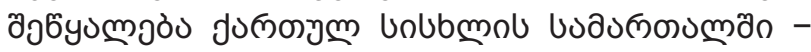

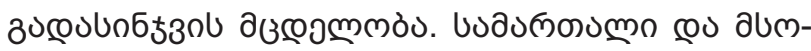
оुмом, №11

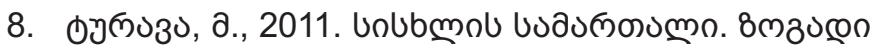

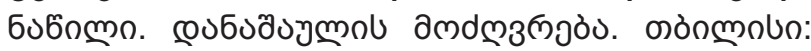

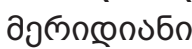

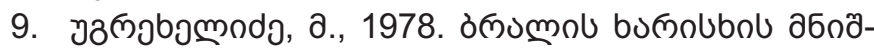

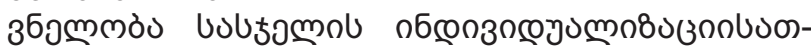

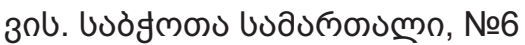

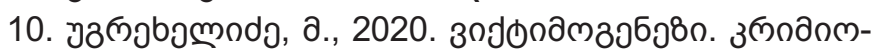

\section{BIBLIOGRAPHY:}

\section{Georgia}

1. Team of Authors (editors: Nachkebia G., Todua N.,) (2018. Criminal Law. General Part. Textbook (Third Edition. Tbilisi: Meridiani (In Georgian)

2. Guruli P. (2015. Personal and Social Integrity as an Object of Infringement in Criminal Law. Proceedings of the Georgian University, Volume II (In Georgian)

3. Guruli P. (2017. Parole - Legimertical Comprehension. Law and the World, №6 (In Georgian)

4. Dvalidze I. (2013. General Part of Criminal Law. Punishment and Other Legal Consequences of Crime. Tbilisi: Meridiani (In Georgian)

5. Ebralidze T. (2016. Entrapment. Otar Gamkrelidze 80. Anniversary Scientific Collection. Tbilisi: Meridiani (In Georgian)

6. Vacheishvili A. (1960. Punishment and Measures of Social Protection. Tbilisi: Stalin Tbilisi State University Publishing House (In Georgian)

7. Meurmishvili B., Guruli P. (2019. Retroactive Force of Penal Legislation and Attempt to Measure the Law. Law and the World, №11 (In Georgian)

8. Turava M. (2011. Criminal Law. General Part. Concept of Crime. Tbilisi: Meridiani (In Georgian)

9. Ugrekhelidze M. (1978. Significance of Degree of Culpability in Terms of Individualisation of Sentence. Soviet Law, №6 (In Georgian)

10. Ugrekhelidze M. (2020. Victimogenesis. Criminologist, №1 (15) (In Georgian)

11. Ghlonti G. (2016. Provocation of Bribery (for Enhancement of Legislation) Otar Gamkrelidze 80. Anniversary Scientific Collection. Tbilisi: Meridiani (In Georgian) 
Бммmmวn, №1 15

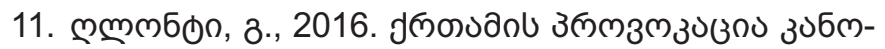

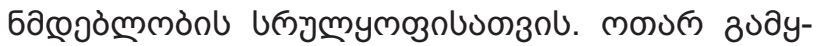

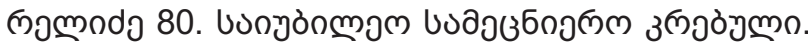

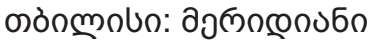

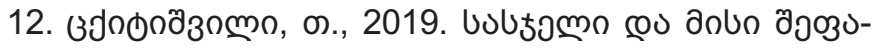

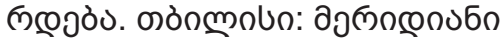

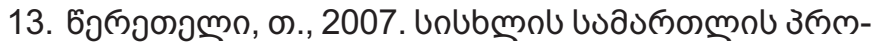

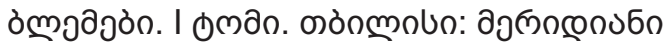

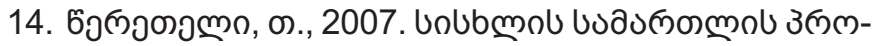

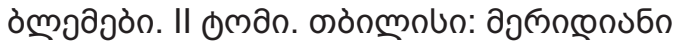

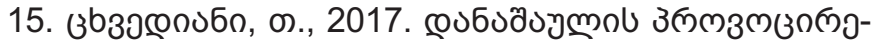

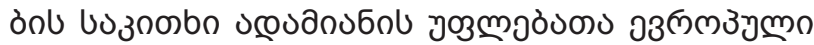

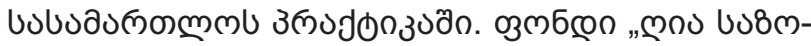

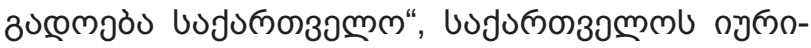

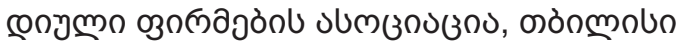

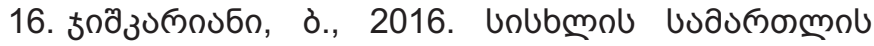

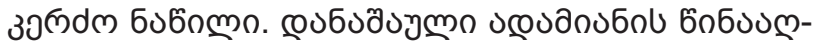

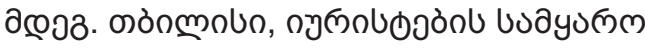

\section{วоตววธธง:}

17. Abegg, J. F., 1969. Die verschiedenen Strafrechtstheorieen in ihrem Verhältnisse zu einander und zu dem positiven Rechte und dessen Geschichte. Erster Theil. Philosophisch-historische Entwicklung des Begriffs von Verbrechen und Strafen. Frankfurt/Main: Verlag Sauer \& Auvermann KG

18. Beccaria, C., 1764. Von Verbrechen und Strafen. Auf das neue selbst aus dem Italienischen übersetzt mit durchgängigen Anmerkungen des Ordinarius zu Leipzig. Breslau

19. Ellbogen, K., 2016. das ende des Polizeichen Lockspitzeleinsatzes? Studere, Rechtszeitschrift der Universität Potsdam, Ausgabe 16, Frühling/Sommer

20. El-Ghazi, M., Zerbes, I., 2014. Geschichten von staatlicher Komplizenschaft und evidenten Rechtsbrüchen. Zugleich Anmerkung zu BGH. HRRS, 15 Jahrgang, Ausgabe 6/2014, Nr. 163

21. Esser, R., 2011. Lockspitzel und V-Leute in der Rechtsprechung des EGMR: Strafrechtliche Ermittlungen jenseits der StPO - außerhalb des Gesetzes? Beitrag zum 35. Strafverteidigertag, Berlin

22. Gottschalk, F., 2013. Verfahrenshindernis bei Tatprovokation durch Lockspitzel? Staatliche Tatprovokationen im Lichte der Rechtsprechung des EGMR. StudZR

23. Grolman, K., 1968. Über die Begründung des Strafrechts und der Strafgesetzgebung. Frankfurt am Main: Verlag Sauer \& Auvermann KG

24. Görlitz, F., Hubert J., Kucher J, Scheffer M., Wieser P. 2019. "Tatprovokation" - The Legal Issue of Entrapment in Germany and Possible Solutions. German Law Journal, 2004

25. Heinrich, B. Staatliche Tatprovokation. 2016. Deutsch-Georgische Strafrechtszeitschrift. 1/2016

26. Hälschner, H., 1858. Das preußische StrafrechtSystem des preußischen Strafrechts Zweiter Theil oder allge-
12. Tskitishvili T. (2019. Punishment and Sentencing. "Meridiani" Publishing house, Tbilisi (In Georgian)

13. Tsereteli T., 2007. Problems of Criminal Law. I Volume. Tbilisi, Meridiani (In Georgian)

14. Tsereteli T., 2007. Problems of Criminal Law. II Volume. Tbilisi, Meridiani (In Georgian)

15. Tskhvediani, T., 2017. The Issue of Entrapment According to the Practice of European Court of Human Rights. Open Society Georgia Foundation. Association Law Firms of Georgia, Tbilisi (In Georgian)

16. Jishkariani B., 2016. Special Part of Criminal Law. Crimes against Human Beings. Tbilisi: World of Lawyers (In Georgian)

\section{Germany:}

17. Abegg, J. F., 1969. Various Theories of Criminal Law in Their Relationship to One Another and to the Positive Law and Its History. First Part. PhilosophicalHistorical Development of the Concept of Crime and Punishment. Frankfurt/Main: Verlag Sauer \& Auvermann KG, (In German)

18. Beccaria, C., 1764. On Crimes and Punishments. Breslau, (In German)

19. Ellbogen, K., 2016. The End of Use of Police Agent Provocateurs? Study, Legal Journal of the University of Potsdam, Issue 16, Spring / Summer (In German)

20. El-Ghazi, M., Zerbes I., 2014. Stories of State Complicity and Obvious Breaches of Law. At the same time, a comment on the FCoJ. HRRS, 15 Volume, Edition 6/2014, Nr. 163 (In German)

21. Esser, R., 2011. Agent Provocateurs and V-people in the Case Law of the ECHR: Criminal Investigations Beyond the GCoCP - Outside the Law? Contribution to the 35th Defense lawyer day, Berlin (In German)

22. Gottschalk, F., 2013. Procedural Obstacle in the Event of a Crime Being Provoked by a Agent Provocateur? State Provocations of Offenses in the Light of the Case Law of the ECHR. StudZR (In German)

23. Grolman K., 1968. About the Establishment of Criminal Law and Criminal Legislation. Frankfurt am Main: Verlag Sauer \& Auvermann KG (In German)

24. Görlitz, F., Hubert J., Kucher J, Scheffer M., Wieser P., 2019. "Tatprovokation" - The Legal Issue of Entrapment in Germany and Possible Solutions. German Law Journal, 20(04) (In German)

25. Heinrich B., 2016. State Entrapment. GermanGeorgian Criminal Law Journal. 1/2016 (In German)

26. Hälschner, H., 1858. The Prussian Criminal Law System of the Prussian Criminal Law Second Part or General Part of the System. By Adolph Marcus. Bonn (In German)

27. Hübner, Y., 2020. Contrary to the Rule of Law, But Unpunishable? The Agent Provocateur and its Consequences Under Criminal Law. Frankfurt am Mein: Nomos (In German) 
meiner Theil des Systems. bei Adolph Marcus. Bonn

27. Hübner, Y., 2020. Rechtsstaatswidrig, aber Straflos? Der agent provocateur-Einsatz und seine Strafrechtlichen Konsequenzen. Frankfurt am Mein: Nomos

28. Hübner, Y., 2020. Schluss mit der Strafzumessungslösung! Zugl. Bespr. zu EGMR (Akbay u.a. gegen Deutschland). HRRS, 21. Jahrgang, №1163

29. Jahn, M., (März, 2021). Schriftliche Stellungnahme für die öffentliche Anhörung im Rechtsausschuss des Deutschen Bundestages. Goethe Universität, Frankfurt am Main

30. Klaus, J., 2021. Das Ende der Strafzumessungslösung nach einer menschenrechtswidrigen Tatprovokation. Zugleich Besprechung von EGMR, Urt. v. 15.10.2020 - 40495/15, 37273/15, 40913/15 (Akbay u.a. v. Deutschland). 16. Volume, Issue 6/2021

31. Köstlin, C.R., 1978. System des deutschen Strafrechts. Allgemeiner Teil. Erste Abteilung. Neudruck der Ausgabe. Tübingen: Scientia Verlag Aalen

32. Roxin, Arzt, Tiedemann. 2013. Einführung in das Strafrecht und Strafprozessrecht. 6 Auflage. C. F. Müller

33. Ugrekhelidze M. 1984. Die Bedeutung des Schuldgehalts der Tat im Strafrecht. Zweites Deutsch-Sowjetisches Kolloquium über Strafrecht und Kriminologie. Baden-Baden: Nomos Verlags-Gesellschaft

34. Von Bar, C. L., 1882. Handbuch des Deutschen Strafrechts. Erster Band. Geschichte des Deutschen Strafrechts und der Strafrechtstheorien. Berlin: Weidmannsche Buchhandlung, §. 95

35. Von Liszt, F., 1905. Strafrechtliche Aufsätze und Vorträge. Der Zweckgedanke im Strafrecht. Erster Band. Berlin: J.Guttentag Verlagsbuchhandlung G.m.b.H

36. Von Feuerbach, P.J.A.R., 1798. Ist Sicherung vor dem Verbrechen Zweck der Strafe und ist Strafrecht Präventionsrecht. Bibliothek für die peinliche Rechtswissenschaft und Gesetzkunde

37. Wessels, Beulke, Satzger. 2020. Strafrecht Allgemeiner Teil. Die Straftat und inr Aufbau. 50, neu bearbeitete Auflage, C.F. Müller

\section{১৪০০लि০:}

38. Liewald, K., 2015. Rechtsfolgen unzulässiger Tatprovokation im Hinblick auf die aktuelle Rechtsprechung des EGMR. Dissertation. Universität Wien, Wien

39. Swoboda, L-S., July 2016. Der „agent provocateur“ aus verwaltungsstrafrechtlicher Sicht. Zeitschrift der Verwaltungsgerichtsbarkeit. Ausgabe 4

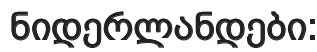

40. Katz, L., 2013. Entrapment Through the Lens of the Actio Libera in Causa. Criminal Law and Philosophy, Volume 7, issue 3, October
28. Hübner, Y., 2020. No More Sentencing Solution! Zugl. Discussion on ECHR (Akbay and Others v. Germany. HRRS, 21. Jahrgang, 2020, №1163 (In German)

29. Jahn, M., March, 2021. Written Statement for the Public Hearing in the Legal Committee of the German Bundestag. Goethe University, Frankfurt am Main (In German)

30. Klaus, J., 2021. The End of the Sentencing Solution After a Human Rights Violation Provocation. At the Same Time Discussion of the ECHR, Ruling. v. 15.10.2020 - 40495/15, 37273/15, 40913/15 (Akbay u.a. v. Germany. 16. Volume, Issue 6/2021 (In German)

31. Köstlin, C. R., 1978) System of German criminal law. General part. First department. Reprint of the edition. Tübingen: Scientia Verlag Aalen (In German)

32. Roxin, Arzt, Tiedemann., 2013. Introduction to criminal law and criminal procedural law. 6th edition. C. F. Müller (In German)

33. Ugrekhelidze, M., 1984. The Meaning of the Degree of Guilt of the Crime in Criminal Law. Second GermanSoviet Colloquium on Criminal Law and Criminology. Baden-Baden: Nomos Verlags-Gesellschaft, (In German)

34. Von Bar, C. L., 1882. Handbook of German Criminal Law. First Volume. History of German Criminal Law and Theories of Criminal Law. Berlin: Weidmannsche Buchhandlung, §. 95 (In German)

35. Von Liszt, F., 1905. Articles and Lectures on Criminal Law. Purpose in Criminal Law. First volume. Berlin: J.Guttentag Verlagsbuchhandlung G.m.b.H., In German)

36. Von Feuerbach P.J.A.R., 1798. Is the Purpose of the Punishment to Protect Against Crime and is Criminal Law Law of Prevention. Library for Criminal Jurisprudence and Legal Studies (In German)

37. Wessels, Beulke, Satzger, 2020. Criminal Law General Part. The Crime and Its Structure. 50th Revised Edition, C.F. Müller (In German)

\section{Austria:}

38. Liewald, K., 2015. Legal Consequences of Inadmissible Offense Provocation with Regard to the Current Case Law of the ECHR. Dissertation. University of Vienna, Vienna (In German)

39. Swoboda L-S., July, 2016. The "Agent Provocateur" From the Point of View of Administrative Criminal Law. Zeitschrift der Verwaltungsgerichtsbarkeit. Edition 4 (In German)

\section{Netherlands:}

40. Katz, L., 2013. Entrapment Through the Lens of the Actio Libera in Causa. Criminal Law and Philosophy, 2013, Volume 7, issue 3, October (In English) 
गзलง०ธ०:

41. Шульгін, С., 2017. Провокація підбурювання особи на вчинення злочину працівниками правоохоронного органу як підстава для закриття кримінального проваждення або постановлення виправдувального вироку. Вісник кримінального судочинства, №1/2017

\section{लyणg0:}

42. Дударенко, В., 2017. Юридическая природа провокации преступления в уголовном праве. Диссертация, Екатеринбург

43. Хейфецъ, И., 1914. Подстрекательство къ преступлению. Москва: изданІЕ юридическаго книжнаго магазина «ПравовђдБнІЕ» И. К. Голубева

\section{Ukraine:}

41. Shulhin, S., 2017. Provocation (Incitement) of a Person to Commit a Crime by Law Enforcement Officers as a Basis For Closing the Criminal Proceedings or Acquittal. Bulletin of Criminal Proceedings. №1/2017 (In Ukrainian)

\section{Russia:}

42. Dudarenko, V., 2017. Legal Nature of Entrapment in Criminal Law. Dissertation, Yekaterinburg (In Russian)

43. Kheifets, I., 1914. Incitement to a Crime. Moscow: Publishing House of Legal Bookstore "Jurisprudence" of I.K. Golubev (In Russian)

NOTES:

1. Shulhin, S., 2017. Provocation (Incitement) of a Person to Commit a Crime by Law Enforcement Officers as a Basis For Closing the Criminal Proceedings or Acquittal. Bulletin of Criminal Proceedings. №1/2017, pp. 96-102

2. Tskhvediani, T, 2017. The Issue of Entrapment According to the Practice of European Court of Human Rights. Open Society Georgia Foundation. Association Law Firms of Georgia, Tbilisi

3. Gottschalk F., 2013. Procedural Obstacle in the Event of a Crime Being Provoked by a Agent Provocateur? State Provocations of Offenses in the Light of the Case Law of the ECHR. StudZR

4. Görlitz, F., Hubert, J., Kucher, J, Scheffer, M., Wieser, P., 2019. "Tatprovokation" The Legal Issue of Entrapment in Germany and Possible Solutions. German Law Journal, 20(04)

5. Liewald, K., 2015. Legal Consequences of Inadmissible Offense Provocation with Regard to the Current Case Law of the ECHR. Dissertation. University of Vienna, Vienna

6. Esser, R., 2011. Agent Provocateurs and V-people in the Case Law of the ECHR: Criminal Investigations Beyond the GCoCP - Outside the Law? Contribution to the $35^{\text {th }}$ Defense lawyer day, Berlin

7. Heinrich, B., 2016. State Entrapment. German-Georgian Criminal Law Journal. $1 / 2016$, pp. $27-28$

8. Ellbogen, K., 2016. The End of Use of Police Agent Provocateurs? Study, Legal Journal of the University of Potsdam, Issue 16, Spring / Summer

9. Wessels, Beulke, Satzger., 2020. Criminal Law General Part. The Crime and Its Structure. 50 ${ }^{\text {th }}$ Revised Edition, C.F. Müller, pp. 4602-4624

10. El-Ghazi, M., Zerbes, I., 2014. Stories of State Complicity and Obvious Breaches of Law. At the same time, a comment on the FCoJ. HRRS, 15 Volume, Edition 6/2014, Nr. 163, pp. 209-219

11. Hübner ,Y., 2020) No More Sentencing Solution! Zugl. Discussion on ECHR (Akbay and Others v. Germany. HRRS, 21. Jahrgang, 2020, №1163, pp. 441-445

12. Dudarenko, V., 2017. Legal Nature of Entrapment in Criminal Law. Dissertation, Yekaterinburg, p. 165

13. Swoboda, L-S., July, 2016) The "Agent Provocateur" From the Point of View of Administrative Criminal Law. Zeitschrift der Verwaltungsgerichtsbarkeit. Edition 4, pp. $304-310$ 
14. Klaus, J., 2021. The End of the Sentencing Solution After a Human Rights Violation Provocation. At the Same Time Discussion of the ECHR, Ruling. v. 15.10.2020 40495/15, 37273/15, 40913/15 (Akbay u.a. v. Germany). 16. Volume, Issue 6/2021, pp. 388-398

15. Jahn, M., March, 2021. Written Statement for the Public Hearing in the Legal Committee of the German Bundestag. Goethe University, Frankfurt am Main, pp. 2-29

16. Tsereteli, T., 2007. Problems of Criminal Law. II Volume. Tbilisi, Meridiani, p. 157

17. Ebralidze, T., 2016. Entrapment. Otar Gamkrelidze 80. Anniversary Scientific Collection. Tbilisi: Meridiani, pp. 132-133

18. Hübner Y., 2020. Contrary to the Rule of Law, But Unpunishable? The Agent Provocateur and its Consequences Under Criminal Law. Frankfurt am Mein: Nomos, p. 152

19. Jishkariani, B., 2016. Special Part of Criminal Law. Crimes against Human Beings. Tbilisi: World of Lawyers, p. 225

20. Dudarenko, V. The work cited, p. 165

21. Ghlonti, G., 2016. Provocation of Bribery (for Enhancement of Legislation) Otar Gamkrelidze 80. Anniversary Scientific Collection. Tbilisi: Meridiani, p. 261

22. Hübner, Y. Contrary to the Rule of Law... pp. 173-173

23. Hübner, Y. Contrary to the Rule of Law... p. 101.

24. Heinrich partially touches this subject. Heinrich B. State Entrapment... p. 25

25. Ellbogen, K. The work cited, p. 65

26. ECtHR. CASE OF GRBA v. CROATIA (Application no. 47074/12) 23 November 2017. § 103

27. Katz, L., 2013. Entrapment Through the Lens of the Actio Libera in Causa. Criminal Law and Philosophy, Volume 7, issue 3, October, pp. 592-595

28. Ugrekhelidze, M., 2020. Victimogenesis. Criminologist, №1 (15), pp. 24-26

29. Ugrekhelidze, M., 2020. Victimogenesis... p. 24-26

30. Ugrekhelidze, M., 1984. The Meaning of the Degree of Guilt of the Crime in Criminal Law. Second German-Soviet Colloquium on Criminal Law and Criminology. Baden-Baden: Nomos Verlags-Gesellschaft, pp. 113-122

31. see in detail: Various Theories of Criminal Law in Their Relationship to One Another and to the Positive Law and Its History. First Part. Philosophical-Historical Development of the Concept of Crime and Punishment. Frankfurt/Main: Verlag Sauer \& Auvermann KG, pp. 8-73

32. Roxin, Arzt, Tiedemann., 2013. Introduction to criminal law and criminal procedural law. 6th edition. C. F. Müller. pp. 4-5

33. Vacheishvili, A., 1960. Punishment and Measures of Social Protection. Tbilisi: Stalin Tbilisi State University Publishing House, pp. 28-31

34. Dvalidze, I., 2013. General Part of Criminal Law. Punishment and Other Legal Consequences of Crime. Tbilisi: Meridiani, p. 18

35. Turava, M., 2011. Criminal Law. General Part. Concept of Crime. Tbilisi: Meridiani, pp. $42-43$

36. Beccaria, C., 1764. On Crimes and Punishments. Breslau, p. 67

37. Vacheishvili, A. The work cited, p. 31

38. Grolman, K., 1968. About the Establishment of Criminal Law and Criminal Legislation. Frankfurt am Main: Verlag Sauer \& Auvermann KG, p. 56

39. Turava, M. The work cited, p. 44.

40. Von Liszt, F., 1905. Articles and Lectures on Criminal Law. Purpose in Criminal Law. First volume. Berlin: J.Guttentag Verlagsbuchhandlung G.m.b.H., pp. 163-179

41. Turava, M. The work cited, p. 44

42. Von Feuerbach, P.J.A.R., 1798. Is the Purpose of the Punishment to Protect Against Crime and is Criminal Law Law of Prevention. Library for Criminal Jurisprudence and Legal Studies

43. Tskitishvili, T., 2019. Punishment and Sentencing. "Meridiani" Publishing house, Tbilisi (In Georgian), pp. 31-32

44. for example, Köstlin, C. R., 1978. System of German criminal law. General part. First department. Reprint of the edition. Tübingen: Scientia Verlag Aalen, pp. 395-413 
45. Team of Authors (editors: Nachkebia G., Todua N.) 2018. Criminal Law. General Part. Textbook (Third Edition). Tbilisi: Meridiani, p. 477

46. ob.: Roxin, Arzt, Tiedemann. The work cited, pp. 6-7

47. Von Bar, C. L., 1882. Handbook of German Criminal Law. First Volume. History of German Criminal Law and Theories of Criminal Law. Berlin: Weidmannsche Buchhandlung, §. 95, pp. 270-273

48. Turava, M. The work cited, p. 46

49. Hälschner, H., 1858. The Prussian Criminal Law System of the Prussian Criminal Law Second Part or General Part of the System. By Adolph Marcus. Bonn, p. 440

50. Meurmishvili, B., Guruli P., 2019. Retroactive Force of Penal Legislation and Attempt to Measure the Law. Law and the World, №1, p. 22

51. Guruli, P., 2017. Parole - Legimertical Comprehension. Law and the World, №6, pp. $48-49$

52. Kheifets, I., 1914. Incitement to a Crime. Moscow: Publishing House of Legal Bookstore "Jurisprudence" of I.K. Golubev, p. 127

53. Tsereteli, T., 2007. Problems of Criminal Law. I Volume. Tbilisi, Meridiani, p. 20

54. Ugrekhelidze, M., 1978. Significance of Degree of Culpability in Terms of Individualisation of Sentence. Soviet Law, №6, p. 47

55. Guruli, P., 2015. Personal and Social Integrity as an Object of Infringement in Criminal Law. Proceedings of the Georgian University, Volume II, p. 296

56. Dvalidze, I., 2013. General Part of Criminal Law... p. 30

57. Guruli, P., 2015. Personal and Social Integrity ... pp. 295-296 